

\section{Sumário}

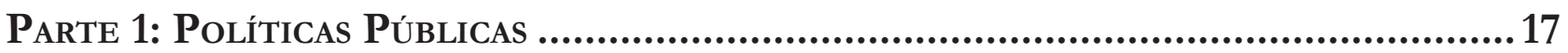

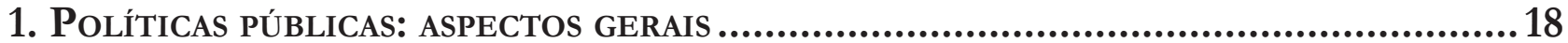

UM MODELO POLÍTICO DE IMPLEMENTAÇÃO PARA AS POLÍTICAS PÚBLICAS: OS PAPÉIS DO DIREITO E DOS JURISTAS.

William H. Clune III

Evaluación de las obras públicas en gobiernos locales en MÉxico: Desafíos de LaS POLÍTICAS PÚBLICAS DE PARTICIPACIÓN CIUDADANA

Louis Valentin Mballa e Arturo Bermúdez Lara

Paternalismo libertário e políticas públicas: intervenção e transparênCia

Marcia Carla Pereira Ribeiro e Victor Hugo Domingues

2. Políticas públicas E COVID-19

LiMITES E POSSIBILIDADES PARA O USO SECUNDÁRIO DE DADOS PESSOAIS NO PODER PÚBLICO: LIÇÕES DA PANDEMIA.

Miriam Wimmer

EFICIÊNCIA DAS POLÍTICAS DE INOVAÇÃO NOS SETORES INDUSTRIAIS BRASILEIROS: SUGESTÕES PARA A CRISE DA COVID-19

Michelle Márcia Viana Martins e Chrystian Soares Mendes

CoMPLIANCE EM TEMPOS DE CALAMIDADE PÚbLICA: ANÁLISE SOBRE A FLEXIBILIZAÇÃo DA TRANSPARÊNCIA DE DADOS E INFORMAÇÕES DURANTE O ENFRENTAMENTO DA COVID-19 NO BrasiL

Luciana Cristina da Conceição Lima, Alcindo Fernandes Gonçalves, Fernando Cardoso Fernandes Rei e Cláudio Benevenuto de Campos Lima

3. Políticas públicas e accountability

ACCOUNTABility E DESENHO INSTITUCIONAL: UM “PONTO CEGO" NO DIREITO PÚBLICO BRASILEIRO

Danielle Hanna Rached

ESTRATÉGIAS REGULATÓRIAS DE COMBATE À CORRUPÇÃo 
O controle e a avaliação pelo Tribunal de Contas da União das políticas públicas IMPLEMENTADAS POR DESONERAÇÕES TRIBUTÁRIAS NO BRASIL

Vinicius Garcia e Carlos Araújo Leonetti

4. Políticas públicas em Matéria de SAÚde

A livre opÇão pela Cesariana: um "NUdge Às aVessas". .268

Bruna Menezes Gomes da Silva e Júlio Cesar de Aguiar

AUTISMO: ASPECTOS JURÍDICOS DA ACESSIBILIDADE E RESPEITO

Fabiana Barrocas Alves Farah e Danilo Fontenele Sampaio Cunha

SAÚdE E DOENÇAS RARAS: ANÁLISE DA JUDICIALIZAÇÃo DO ACESSO AO TRATAMENTO E SUAS LIMITAÇÕES.

Danilo Henrique Nunes e Lucas de Souza Lehfeld

5. OUTRAS POLÍTICAS PÚBLICAS EM ESPÉCIE

REGUlAÇÃO DAS ÁGUAS: UMA ANÁLISE EMPÍRICA DA PRODUÇÃo NORMATIVA DOS ÓRGÃOS REGULADORES FEDERAIS

Bianca Borges Medeiros Pavão, Natasha Schmitt Caccia Salinas e Thauany do Nascimento Vigar

“LET THE ALGORITHM DECIDE": IS HUMAN DIGNITY AT STAKE?.

Marcela Mattiuzzo

DAS ACEPÇÕES DOS DIREITOS DOS REFUGIADOS ÀS VOZES SILENCIADAS NAS POLÍTICAS PÚBLICAs371 Thaís Araújo Dias e Monica Mota Tassigny

Planejamento familiar: “inimigo" a Ser combatido, “aliado” libertador ou falso "AMIGO"?

Vinicius Ferreira Baptista

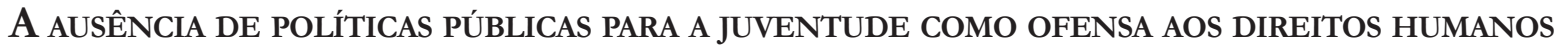
William Timóteo e llzver de Matos Oliveira

AnÁlise CÊniCa dos feminicídios em Curitiba: propostas preventivas e repressivas ....433 Ticiane Louise Santana Pereira, Octahydes Ballan Junior e Antonio Henrique Graciano Suxberger

ORIGIN AND CONSEQUENCES OF THE WAR ON DRUGS. FROM THE UNITED STATES TO ANDEAN COUNTRIES

Silvio Cuneo e Nicolás Oxman 
Trabalho Decente: comportamento Ético, política pública ou Bem JuRIDiCamente TUTELADO?.

Silvio Beltramelli Neto e Mônica Nogueira Rodrigues

El FINAL DE UNA POLÍtica PÚBLICA: ANÁLISIS DEL CICLO POLÍTICO DEL PROYECTO DESTINOS INDUCTORES PARA EL DESARROLLO TURISTICO REGIONAL (DIDTR) - BRASIL. .496

María Belén Zambrano Pontón, Magnus Luiz Emmendoerfer e Suely de Fátima Ramos Silveira

Alternativa tecnológica para COMPensaÇão de CRÉditos de ICMS: ESTUdo de Caso da VIABILIDADE DO USO DE DLT EM NOTA FISCAL ELETRÔNICA .520

Danielle Mendes Thame Denny, Roberto Ferreira Paulo e Fernando Crespo Queiroz Neves

Parte 2: Temas Gerais

A construção do Direito Humano ao Alimento no plano internacional. 551 Tatiana de A. F. R. Cardoso Squeff

Grupos vUlNERABles de ESPECIAL PROTECCIÓN POR PARTE DEL INSTITUTO NACIONAL DE Derechos Humanos (INDH) ¿EN QUIÉN PODRÍA Y DEBERÍA ENFOCARSE EN BASE A LA DOCTRINA Y A LA EXPERIENCIA COMPARADA IBEROAMERICANA?

Juan Pablo Díaz Fuenzalida

El SUFRAGIO ELECTRÓNICO COMO ALTERNATIVA AL SUFRAGIO TRADICIONAL: LUCES Y SOMBRAS DE UN DEBATE RECURRENTE 595

David Almagro Castro, Felipe Ignacio Paredes Paredes e Edgardo Lito Andres Cancino

Cognoscibilidade E CONTROLE SOCIAL dA TRANSPARÊNCIA PÚbliCA SOB A ÉGIDE DA DEMODIVERSIDADE: ESTUDO EMPÍRICO DE PORTAIS ELETRÔNICOS MINISTERIAIS LATINOAMERICANOS

Ana Carolina Campara Verdum, Leonardo Fontana Trevisan e Rosane Leal da Silva

DESAFIOS E BENEFÍCIOS DA INTELIGÊNCIA ARTIFICIAL PARA O DIREITO DO CONSUMIDOR 655 Sthéfano Bruno Santos Divino

QUEM TEM MEDO DA RESPONSABILIZAÇÃo SUBJETIVA? As TEORIAS DA CONDUTA E DA IMPUTAÇÃO, PARA UM DIREITO ADMINISTRATIVO SANCIONADOR CONSTITUCIONALIZADO...........................690 Sandro Lúcio Dezan e Paulo Afonso Cavichioli Carmona

A INSUfiCiÊNCIA dE TRIBUTAÇÃo COMO FUNDAMENTO PARA O AFASTAMENTO DA RESERVA DO POSSÍVEL NA GARANTIA DO MÍNIMO EXISTENCIAL E DA DIGNIDADE HUMANA. 711 Dione J. Wasilewski e Emerson Gabardo 


\title{
Estratégias regulatórias de combate à corrupção*
}

\section{Regulatory strategies for tackling corruption}

\author{
Eduardo Jordão** \\ Luiz Carlos Penner Rodrigues da Costa***
}

\section{Resumo}

O artigo tem por objetivos (i) classificar as estratégias anticorrupção na taxonomia já proposta pela literatura para as estratégias regulatórias e (ii) apontar as aplicações e as vantagens genéricas e específicas de cada uma das estratégias identificadas. Para tanto, é feita uma pesquisa descritiva, que busca analisar e mapear as estratégias de combate à corrução adotadas nos contextos brasileiro e internacional, agrupando-as em quatro categorias: comando e controle, transparência, incentivos e instituições. Entre as conclusões tiradas do estudo realizado, verifica-se que, se, por um lado, o investimento concentrado em uma só estratégia não solucionará problemas ligados ao combate à corrupção; por outro, a combinação de estratégias também pode gerar custos e riscos como os derivados da descoordenação regulatória. Ademais, percebe-se que há uma tendência de sofisticação e de custos crescentes para lidar com os problemas ligados à corrupção, o que, embora possa aumentar a efetividade das medidas, também traz dificuldades à medida que as estratégias se distanciam da simplicidade. $\mathrm{O}$ trabalho se justifica porque o mapeamento e a classificação realizados permitem entender as naturezas das estratégias existentes e suas vantagens e desvantagens quando aplicadas a diferentes contextos, o que viabilizará uma futura análise compreensiva sobre a qualidade das iniciativas anticorrupção propostas no Brasil. Além disso, embora existam diversos trabalhos publicados com revisões de literatura e de leis anticorrupção, não havia, na literatura nacional, análise abrangente que sistematizasse essas estratégias de forma a compatibilizá-las com a literatura que trata da Teoria da Regulação.

Palavras-chave: Corrupção. Regulação. Estratégias regulatórias.

* Recebido em 10/07/2020

Aprovado em 16/02/2021

** Professor da FGV Direito Rio e sócio do Portugal Ribeiro Advogados. Doutor pelas Universidades de Paris e de Roma. Mestre pela USP e pela LSE. Foi pesquisador visitante em Harvard, Yale, MIT e Institutos Max Planck. E-mail: eduardo.jordao@fgv.br

*** Mestrando em Direito da Regulação pela FGV Direito Rio. Pesquisa realizada com apoio da CAPES - Código de Financiamento 001 e com o apoio financeiro da Fundação Getulio Vargas. E-mail: luizcprdacosta@gmail.com

\section{Abstract}

The objectives of the paper are (i) to classify the anti-corruption strategies using the taxonomy already presented by the literature on regulatory strategies and (ii) to point out applications and generic and specific advantages of each of such strategies. For this purpose, we carry out a descriptive research that aims to analyze and map the strategies for tackling corruption adopted in Brazil and abroad, grouping them in four categories: command and control, transparency, incentives and institutions. Among the conclusions drawn from the study, we observe that, if on the one hand concentrated efforts in 
only one strategy will not solve anti-corruption problems, on the other hand the combination of strategies may also create unwanted costs and risks, such as lack of regulatory coordination. Moreover, we identified a trend of increasing sophistication and costs in tackling corruption, which could increase the effectiveness of the measures, but at the cost of creating difficulties as they move away from simplicity. The importance of the research lies in the fact that the mapping and classification that were held allow us to understand the nature of the implemented strategies and their advantages and disadvantages when applied in different contexts, which will enable a future comprehensive and exhaustive analysis on the quality of the anti-corruption initiatives proposed in Brazil. Furthermore, although there are several papers that review the literature and the law on anti-corruption strategies, there were no comprehensive and systematic studies that tried to reconcile them with the literature on regulatory theory.

Keywords: Corruption. Regulation. Regulatory strategies.

\section{Introdução}

Dois episódios recentes modificaram a forma como a população brasileira enxerga a corrupção: o Mensalão e, principalmente, a Operação Lava Jato. Em 2018, o índice de percepção de corrupção apontou para uma pontuação de 35 para o Brasil, o menor valor em sete anos, o que colocou o país em $105^{\circ}$ lugar, dentre os 180 países analisados, juntamente à Argélia, Armênia, Costa do Marfim, Egito, El Salvador, Peru, Timor Leste e Zâmbia. ${ }^{1}$ A corrupção se reflete não apenas na opinião da população, mas também em perdas econômicas para o país. Naturalmente, os efeitos econômicos da corrupção são de difícil mensuração, ${ }^{2}$ de modo que as estimativas variam muito, mas sempre em torno de valores muito expressivos. Em uma delas, a corrupção em governos locais é responsável por perdas de, aproximadamente, 550 milhões de dólares por ano. ${ }^{3}$ Em outra, a perda seria de 200 bilhões de reais por ano. ${ }^{4}$

Nesse contexto, o combate à corrupção é um tema que, por si só, justifica o desenvolvimento de uma agenda acadêmica no Brasil. Para contribuir com essa agenda, buscamos mapear as principais estratégias anticorrupção adotadas ao redor do mundo, agrupando-as dentre quatro categorias de estratégias desenvolvidas no âmbito da Teoria da Regulação: comando e controle, informação (transparência), incentivos e instituições (design). A partir dessa categorização, apresentaremos as principais vantagens e desvantagens de cada estratégia, juntamente a exemplos não exaustivos de sua aplicação no Brasil e no mundo. Trata-se, portanto, de um trabalho descritivo que tem dois objetivos: (i) classificar as estratégias anticorrupção dentro da taxonomia já proposta para as estratégias regulatórias e (ii) apontar vantagens - genéricas, apresentadas na literatura de estratégias regulatórias e que podem ser aplicadas a corrupção; e específicas, advindas da literatura específica sobre combate à corrupção - e aplicações de cada uma das estratégias no contexto brasileiro e internacional.

Consoante Julia Black, este é um artigo que tem de ser escrito antes de que possamos escrever o artigo que queremos. Isto é, para que seja possível fazer, futuramente, uma análise compreensiva e exaustiva sobre a qualidade das iniciativas anticorrupção propostas no Brasil - e eventualmente apontar os rumos que devem ser tomados -, é necessário, primeiramente, entender quais são as ferramentas de combate à corrupção disponíveis, seus prós e contras. Na literatura brasileira, foi possível verificar apenas um artigo - escrito por

\footnotetext{
1 Dados disponíveis em: https://www.transparency.org/cpi2018. Acesso em 21 jun. 2019.

2 POWER, Timothy Joseph; TAYLOR, Matthew MacLeod. Corruption and democracy in Brazil: the struggle for accountability. Notre Dame: University of Notre Dame Press, 2011. p. 1.

3 FERRAZ, Claudio; FINAN, Frederico. Electoral accountability and corruption: Evidence from the audits of local governments. The American Economic Review, v. 101, n. 4, p. 1274-1311, 2011.

4 Corrupção desvia R\$2 200 bi, por ano, no Brasil, diz coordenador da Lava Jato, disponível em: https://politica.estadao.com.br/blogs/ fausto-macedo/corrupcao-desvia-r-200-bi-por-ano-no-brasil-diz-coordenador-da-lava-jato/. Acesso em: 21 jun. 2019.
} 
Mariana Prado e Lindsey Carson em 20145 - em que houve tentativas de mapeamento das estratégias anticorrupção com foco no Brasil e utilizando a literatura internacional de combate à corrupção.

O desenvolvimento deste trabalho se dará da seguinte forma. $\mathrm{Na}$ seção 2, apresentaremos a estratégia de comando e controle como uma das modalidades mais usuais de combate à corrupção, tanto por meio da proibição direta de condutas quando pela proibição de circunstâncias favoráveis à corrupção. Na seção 3, apresentaremos os mecanismos de transparências ou de informação, que partem da premissa de que há um problema do tipo principal-agente no caso da corrupção, uma vez que atores corruptos (agente) buscarão seus próprios objetivos pessoais ao invés de perseguir o bem coletivo da população (principal). Para aumentar a probabilidade de que a atuação do agente se alinhe às expectativas do principal, busca-se aumentar a probabilidade de que agentes corruptos sejam identificados pela população ou simplesmente busca-se aumentar a quantidade de informações disponíveis para que a população possa fazer a fiscalização e eventualmente descubra atos corruptos. Na seção 4, analisaremos mecanismos de incentivos, destacando-se o aumento de salários de funcionários públicos e utilização de acordos de leniência e colaboração premiada. Já na seção 5 , avaliaremos como o design de agências anticorrupção - tanto a criação de agências voltadas especificamente para esta finalidade quando a criação de sobreposições institucionais - pode ser efetivo no combate à corrupção. $\mathrm{Na}$ seção 6, realizaremos uma síntese dos principais pontos desenvolvidos ao longo do trabalho.

\section{Comando e controle}

A primeira e mais evidente forma de usar o direito para prevenir a corrupção consiste em estabelecer proibições. Em experimento realizado por Daniel Kaufmann em 1997, perguntou-se a 150 gerentes e funcionários públicos de países com altos índices de corrupção quais seriam, em suas opiniões, as estratégias anticorrupção mais efetivas. ${ }^{6}$ A maioria acreditava que a rotação de funcionários e o aumento de penas apresentariam os melhores resultados.

$\mathrm{Na}$ literatura de regulação, o aumento de pena faz parte de estratégia regulatória mais ampla conhecida como comando e controle: criam-se regras que impõem ou prescrevem determinadas condutas e controla-se sua observância. Com base nesta mesma estratégia, no entanto, há, pelo menos, duas possibilidades que devem ser apartadas. Numa primeira hipótese, a proibição incidirá, diretamente, a conduta que se quer proscrever, ou seja, a conduta afastada é precisamente aquela que configuraria o ato de corrupção. Numa segunda hipótese, o legislador se antecipa e proíbe não a corrupção em si, mas a configuração de uma situação em que a corrupção é provável; o que o legislador faz, nesse caso, é atuar para evitar que se estabeleçam circunstâncias favoráveis ao cometimento de ilícitos.

\subsection{Proibição direta de condutas}

Naturalmente, são muitas as proibições ou determinações de condutas que podem ser atribuídas a uma intenção do legislador de prevenir a corrupção. No caso de proibições diretas, o legislador busca a utilização de estratégias de comando e controle para, uma vez que uma pessoa tente realizar atos corruptos, (i) não tenha os meios disponíveis à disposição - meios que são estritamente vinculados à realização de atos de corrupção, o que difere da categoria de proibições indiretas apresentada na seção 2.2 ou, (ii) ainda que tenha os meios, seja devidamente punido caso intente se envolver em atos proibidos.

Um exemplo de tentativa de proibição direta de condutas corruptas é dada pela Lei 8.112/90 ("Estatuto

\footnotetext{
CARSON, Lindsey; PRADO, Mariana Mota. Carson, Lindsey D. and Prado, Mariana Mota, Mapping Corruption \& its Institutional Determinants in Brazil. IRIBA Working Paper, n. 08, 2014.

6 KAUFMANN, Daniel. Corruption: the facts. Foreign policy, p. 114-131, 1997.
} 
dos Servidores Públicos"). Para tanto, estabelece uma série de proibições no que seria a causa da corrupção, dado que os casos de corrupção que envolvem dinheiro público usualmente requerem o concurso ou a negligência de algum funcionário público. Pró́be, por exemplo, a prática de nepotismo, a utilização de cargo público para proveito pessoal ou de terceiros (inclusive a proibição textualmente expressa de receber propina) e a utilização de recursos públicos em prol de atividades particulares. Essas previsões de deveres e proibições funcionais são relevantes na medida em que funcionam como gatilhos para a sua responsabilização administrativa, e também como aspectos relevantes de sua responsabilização civil e penal. ${ }^{7}$ Ainda, essas responsabilizações poderão ser cumuladas e independem uma das outras.

A Lei 8.666/93, sobre licitações e contratos administrativos, caminha no mesmo sentido, partindo do pressuposto de que as contratações públicas são ocasiões muito propícias para a prática de corrupção e que, portanto, devem ser minuciosamente reguladas. Com base na perspectiva pública, pode o Estado manejar o seu poder de compra e o seu potencial econômico para favorecer determinados agentes econômicos. Contratações públicas, que deveriam servir à satisfação de necessidades públicas, podem, assim, esconder transferências indevidas de recursos em benefício de partes privadas. Com base na perspectiva privada, os procedimentos licitatórios podem ser frustrados por meio de colusão entre potenciais licitantes para permitir uma venda de bens ou serviços com sobrepreço. Regular as contratações públicas é, em grande medida, estabelecer as condições adequadas para dificultar ou impedir a realização destas situações. A maior parte das normas contidas na lei visam a garantir a competitividade do certame licitatório.

Para alcançar esse objetivo, a lei veda a participação na licitação do autor do projeto básico ou executivo, as práticas que limitam as exigências de qualificação técnica ou econômico financeira, ou que restrinjam a participação de consórcios entre os licitantes. E, finalmente, também é relevante o fato de a lei de licitações ter criminalizado várias das condutas que poderiam frustrar o seu ideal de competitividade, tais como "[d] ispensar ou inexigir licitação fora das hipóteses previstas em lei", "frustrar ou fraudar, mediante ajuste, combinação ou qualquer outro expediente, o caráter competitivo do procedimento licitatório, com o intuito de obter, para si ou para outrem, vantagem decorrente da adjudicação do objeto da licitação"; "[p]atrocinar, direta ou indiretamente, interesse privado perante a Administração, dando causa à instauração de licitação ou à celebração de contrato, cuja invalidação vier a ser decretada pelo Poder Judiciário"; e "devassar o sigilo de proposta apresentada em procedimento licitatório, ou proporcionar a terceiro o ensejo de devassá-lo". Adicione-se que, de acordo com o art. 83, o cometimento dos crimes ali previstos sujeita os seus autores, quando servidores públicos, além das sanções penais, à perda do cargo, emprego, função ou mandato eletivo.

Vistos esses exemplos mais gerais de proibições diretas de condutas, é necessário avaliar suas vantagens e desvantagens. Uma das vantagens mais evidentes associadas a essa estratégia é a possibilidade de utilizar a lei para impor regras ou standards de maneira imediata, proibindo as atividades que não estejam de acordo com a determinação legal, como no caso da proibição da utilização do cargo para favorecimento pessoal. Em termos políticos, a criação de uma norma é uma mensagem clara de que o regulador está tomando uma posição forte para resolver o problema. Ou seja, a norma está sendo utilizada com um objetivo simbólico e prático. ${ }^{8}$

Um exemplo do poder simbólico da mensagem sobre o combate à corrupção por meio da utilização de estratégias de comando e controle é o Projeto de Lei 4.850/2016 ("Dez Medidas Contra a Corrupção"). A justificativa do projeto de lei se inicia com o apelo ao sentimento da população ao afirmar que a "sociedade brasileira assiste estarrecida" ao aumento de "denúncias sobre corrupção e enriquecimento ilícito de agentes públicos", o que fez com que brotasse "um grito neste março de 2016" a partir "da movimentação das ruas". Ou seja, trata-se de projeto de lei diretamente voltado a atender aos anseios populares frente ao agravamento da percepção de corrupção surgidos a partir da Operação Lava Jato.

GOMES, Reginaldo Gonçalves. Responsabilidade Administrativa do Servidor Público na Administração Pública Federal. Prisma Jurídico, v. 13, n. 1, p. 193-212, 2014.

8 BALDWIN, Robert; CAVE, Martin; LODGE, Martin. Understanding regulation: theory, strategy, and practice. New York: Oxford University Press, 2012. p. 106-111. 
Para tanto, dentre as dez medidas apresentadas, nove podem ser classificadas como comando e controle, ou como medidas que tentem solucionar problemas de enforcement associados ao estabelecimento de regras: (i) criminalização do enriquecimento ilícito de agentes públicos, (ii) aumento das penas e crime hediondo para corrupção de altos valores, (iii) aumento da eficiência e da justiça dos recursos no processo penal, (iv) celeridade nas ações de improbidade administrativa, (v) reforma no sistema de prescrição penal, (vi) ajustes nas nulidades penais, (vii) responsabilização dos partidos políticos e criminalização do caixa 2, (viii) prisão preventiva para evitar a dissipação do dinheiro desviado e (ix) recuperação do lucro derivado do crime. ${ }^{9}$ Em resumo, essas medidas tratam do aumento de penas ou da modificação das regras penais e de processo penal para, em tese, diminuir os incentivos daqueles atores que pretendam participar de condutas corruptas. Apenas a medida de "prevenção à corrupção, transparência e proteção à fonte de informação" pode ser caracterizada como não sendo relacionada a estratégias de comando e controle, privilegiando estratégias de informação e de incentivos.

Contudo, a utilização de estratégias de comando e controle também apresenta problemas, como a reduzida flexibilidade e os seus custos elevados tanto para criação das regras, como para controlá-las. ${ }^{10}$ Esses custos podem se manifestar de diversas formas.

A mais evidente é a quantidade de informação necessária para a criação de regras. A opção pela criação de regras específicas para regular determinada atividade envolve a análise sobre os custos em que se deve incorrer, uma vez que a criação de regras implica o aumento de custos no momento de sua elaboração para, em tese, buscar-se diminuir estes custos no momento de sua aplicação. ${ }^{11}$ Ocorre que, eventualmente, os custos de busca e processamento de informações podem ser proibitivos, principalmente em um cenário de incerteza ou até mesmo de ignorância. Nesses casos, investir em regras pode não ser o melhor caminho. É justamente nesses casos em que a utilização de regras dá lugar à utilização de princípios. O Estatuto dos Servidores Públicos parece se encaminhar nesse sentido - ao menos em complementação às regras já discutidas acima -, ao estabelecer obrigações de "zelar pela economia material e a conservação do patrimônio público" e "manter conduta compatível com a moralidade administrativa”. A Lei 8.666/93 caminha no mesmo sentido, na medida em que, juntamente às regras específicas de contratações, estabelece princípios genéricos, como a vantajosidade da contratação, impessoalidade, moralidade, igualdade, publicidade, probidade administrativa.

O uso da estratégia de comando e controle gera também um risco de legalismo, uma tendência de gerar normas inflexíveis, intervindo em liberdades administrativas dos regulados. Esse fato é agravado pela criação excessiva de regras com o objetivo de reduzir a discricionariedade do administrador. ${ }^{12}$ Por exemplo, em uma licitação, as hipóteses de dispensa de licitação são previstas, taxativamente, no art. 24 da Lei 8666/93. Reduzir a discricionariedade nesse caso significou criar uma lei com trinta e quatro incisos. O segundo possível agravante ao legalismo é a tendência do legislador de regular rapidamente com base em casos que tenham ocorrido, antes que a população em geral os esqueça. ${ }^{13}$

Outro custo regulatório é de enforcement, sendo muito dispendioso principalmente porque dá espaço para a conformidade criativa (creative compliance) e também há um grande risco de judicialização. ${ }^{14} \mathrm{O}$ próprio Es-

\footnotetext{
9 Para uma descrição mais detalhada, conferir: As 10 Medidas Contra a Corrupção: Propostas do Ministério Público Federal para o combate à corrupção e à impunidade. Disponível em: http://www.dezmedidas.mpf.mp.br/campanha/documentos/resumo-medidas.pdf. Acesso em: 14 jun. 2019.

10 BALDWIN, Robert; CAVE, Martin; LODGE, Martin. Understanding regulation: theory, strategy, and practice. New York: Oxford University Press, 2012. p. 106-111.

11 Em taxonomia apresentada por Sustein e Margalit (1999), a criação de regras é uma estratégia de segunda ordem do tipo bigh-low, no sentido de que envolve justamente o aumento de custos ex ante (no momento de sua elaboração) na expectativa de reduzi-los no momento de sua aplicação (ex post). SUNSTEIN, Cass R; ULLMANN-MARGALIT, Edna. Second-order decisions, Ethics, v. 110, n. 1, p. 5-31, 1999. p. 5-6 e 21-26.

12 BALDWIN, Robert; CAVE, Martin; LODGE, Martin. Understanding regulation: theory, strategy, and practice. New York: Oxford University Press. 2012. p. 108.

13 BALDWIN, Robert; CAVE, Martin; LODGE, Martin. Understanding regulation: theory, strategy, and practice. New York: Oxford University Press, 2012. p. 108.

14 No Quênia, por exemplo, a criação de leis foi bastante utilizada como estratégia política, mas sem efeitos práticos, principal-
} 
tatuto dos Servidores Públicos, apesar de proibir o nepotismo, abriu espaço para a conformidade criativa, na medida que agentes públicos passaram a se utilizar do nepotismo cruzado - em que o agente público A indica um familiar do agente público B enquanto o B indica um familiar de A. ${ }^{15}$

Ainda sobre enforcement, a existência da legislação por si só não é suficiente para o combate à corrupção, é necessário que haja monitoramento. Em alguns locais, o nível de detecção e punição de atos corruptos não será alcançado porque não há monitoramento suficiente ou porque há uma corrupção sistêmica - inclusive permeando os atores responsáveis pela aplicação da lei. Nesses casos, mesmo que haja uma tentativa de, apesar do baixo monitoramento, garantir a punição severa dos indivíduos detectados em atos corruptos, pode ser que poucas cortes queiram sancioná-los draconianamente. ${ }^{16}$

Tentando lidar com o problema do enforcement, a Lei Complementar 101/00 ("Lei de Responsabilidade Fiscal"), apesar de não ter o combate à corrupção entre suas principais finalidades, estabelece regras rígidas para a transferência (direta ou indireta) de recursos públicos para particulares. Também contribui para a ampliação da transparência no manejo das contas e dos orçamentos públicos.

A efetividade de estratégias anticorrupção baseadas no aumento do monitoramento ou no aumento das sanções depende, ainda, do nível de corruptibilidade daquela sociedade. Se o nível de corrupção for alto, a utilização de sanções mais rígidas provavelmente não será efetiva, já que os atores corruptos continuam a acreditar que a chance de serem descobertos e efetivamente punidos é baixa, podendo, inclusive, subornar o agente responsável pela investigação ou sanção. Igualmente, aumentar a possibilidade de que a pessoa possa ser descoberta pode ser ineficaz nos casos em que os indivíduos continuam podendo subornar os oficiais encarregados do monitoramento, para não os monitorar adequadamente. ${ }^{17}$

Outra forma de ineficácia do aumento de sanções ocorre se a população considera aquela sanção injusta. ${ }^{18}$ Tanzi e Shome realizaram estudo em 1993 no qual mostram que, se houver um aumento da pena para sonegação de impostos, será mais provável que a sociedade não esteja disposta a aplicar sanções sobre as pessoas que forem descobertas, principalmente porque, nas palavras dos autores, "várias sociedades se sentiriam desconfortáveis em escolher e punir indivíduos particulares, quase que em um processo de loteria, ao mesmo tempo em que vários outros indivíduos podem ter cometido as mesmas transgressões”.

Além disso, muitas vezes a utilização de leis para reduzir níveis de corrupção gera outros problemas, como ocorreu em Bangladesh. O governo resolveu acabar com o problema de corrupção usando a força para obrigar as pessoas a não praticarem atos corruptos, o que fez com que logo perdesse qualquer apoio da população que inicialmente tinha. Simplesmente não houve suporte popular para sustentar estratégia de longo prazo por meio do endurecimento de regras. ${ }^{19}$

mente pela existência de leis pouco precisas que poderiam ser interpretadas de acordo com a vontade do governo. Nesse caso, portanto, "without 'buy in' from prominent stakeholders top-down attempts to cleanse public life are destined not just to fail but to fail badly". HOUGH, Dan. Corruption, anti-corruption and governance. UK: Palgrave Macmillan, 2013. p. 65-68.

15 Essa prática foi objeto de súmula vinculante do STF, (Súmula Vinculante no 13) estabelecendo que "a nomeação de cônjuge, companheiro ou parente em linha reta, colateral ou por afinidade, até o terceiro grau, inclusive, da autoridade nomeante ou de servidor da mesma pessoa jurídica, investido em cargo de direção, chefia ou assessoramento, para o exercício de cargo em comissão ou de confiança, ou, ainda, de função gratificada na Administração Pública direta e indireta, em qualquer dos Poderes da União, dos Estados, do Distrito Federal e dos municípios, compreendido o ajuste mediante designações recíprocas, viola a Constituição Federal". 16 OGUS, Anthony. Corruption and regulatory structures. Law \& Policy, v. 26, n. 3-4, p. 329-346, 2004. p. 336.

17 RYVKIN, Dmitry; SERRA, Danila. How corruptible are you? Bribery under uncertainty. Journal of Economic Behavior \& Organization, v. 81, n. 2, p. 466-477, 2012. p. 472; OLKEN, Benjamin A. Monitoring corruption: evidence from a field experiment in Indonesia. Journal of political Economy, v. 115, n. 2, p. 200-249, 2007. p. 201.

18 AKERLOF, George A; YELLEN, Janet L. The fair wage-effort hypothesis and unemployment. The Quarterly Journal of Economics, v. 105, n. 2, p. 255-283, 1990; VAN RIJCKEGHEM, Caroline; WEDER, Beatrice. Bureaucratic corruption and the rate of temptation: do wages in the civil service affect corruption, and by how much?. Journal of development economics, v. 65, n. 2, p. 307-331, 2001. p. 7.

19 HOUGH, Dan. Corruption, anti-corruption and governance. UK: Palgrave Macmillan, 2013. p. 58. 


\subsection{Proibição de circunstâncias favoráveis à corrupção}

Outra forma de manejar a estratégia regulatória de comando e controle para combater a corrupção consiste não em proibir diretamente alguma conduta que se quer ver afastada, mas em evitar que se configurem as circunstâncias que facilitariam a sua realização. Trata-se de estratégia comum, que possui vantagens e desvantagens em relação à proscrição direta de condutas. De um lado, ela possui resultado incerto, na medida em que os efeitos concretos de prevenção são, apenas, esperados em função do ambiente específico desfavorável que se cria. De outro lado, sua efetividade no combate à corrupção pode ser acentuada, na medida em que incide mesmo antes de que se criem as condições facilitadoras das infrações.

Vários são os exemplos encontrados nos mais diversos diplomas legislativos. Mas, talvez, o mais interessante deles esteja contido na Lei 12.812/12, sobre conflito de interesses no exercício de cargo ou emprego do Poder Executivo federal e impedimentos posteriores ao exercício do cargo ou emprego. O objetivo geral da lei é evitar que funcionários públicos de alto escalão se valham de informações privilegiadas e sensíveis a que tenham acesso, durante o exercício do cargo ou do próprio poder de influência obtido nessas circunstâncias, para obter vantagens econômicas ou financeiras para si ou para terceiros. Trata-se de iniciativa voltada à prevenção de corrupção. À lei se submetem ocupantes de cargos de Ministro de Estado, Presidente, Vice-Presidente e diretores de autarquias, fundações públicas, empresas públicas e sociedades de economia mista, além de funcionários DAS de nível 6 ou 5. Mas, em boa parte de suas disposições, a lei não proscreve ou pune diretamente a transferência de informações privilegiadas ou a sua utilização. Ao invés disso, a lei proscreve até mesmo que esses agentes venham a ocupar cargos em que essas informações lhes seriam solicitadas.

Mecanismo similar foi utilizado de forma bem-sucedida em Hong Kong. Um dos fatores essenciais para que a estratégia anticorrupção tenha sido efetiva foi a implementação de códigos de conduta que obrigavam os funcionários de determinados setores a declarar quaisquer interesses pecuniários ou econômicos que estivessem em conflito com suas obrigações legais. ${ }^{20}$ Estas são informações que podem, eventualmente, ser utilizadas para evitar que esses funcionários sejam incumbidos de funções em que surjam potenciais conflitos de interesses e, consequentemente, cenários propícios para a corrupção.

Uma segunda forma bastante comum de promover essa estratégia regulatória preventiva consiste em prever o afastamento cautelar de agentes investigados por corrupção para evitar que repita a infração ou atrapalhe a sua apuração. Assim, o art. 147 do Estatuto dos Servidores prevê a possibilidade de afastamento preventivo de servidor investigado, pelo prazo de até 60 dias, prorrogável por igual período.

Em casos um pouco diferentes, essa estratégia preventiva decorre de uma específica interpretação de dispositivos legais, consagrado na jurisprudência dos órgãos de controle $\square$ e não já da lei em si. Assim, por exemplo, a lei de licitações estabelece a possibilidade de realização da chamada "visita técnica" de potenciais licitantes, para fins de reconhecimento das condições locais impactantes sobre o cumprimento das obrigações objeto da licitação (art. 30, III). Mas a lei não regulamenta essa visita, nem estabelece como ela se dará. O Tribunal de Contas da União tem entendido, no entanto, que a administração não pode restringi-la a horários fixos "no intuito de inibir que os potenciais licitantes tomem conhecimento prévio do universo de concorrentes". ${ }^{21} \mathrm{O}$ que o TCU faz aqui é atuar para evitar que se constitua um estado de coisas facilitador da colusão entre licitantes.

Por fim, uma hipótese explorada pela literatura norte-americana é da possibilidade de que, eventualmen-

\footnotetext{
20 HUI, Wingchi. Combating Corruption: The Hong Kong Experience (October 31, 2013). Tsinghua China Law Review, v. 6, p. 250, 2013.

21 TCU, Acórdão n. ${ }^{\circ}$ 3119/2010, publ. 22/06/2010: “1.6.2. alertar a [...], para que, nos futuros procedimentos licitatórios que envolvam recursos públicos federais, haja observância das seguintes orientações: [...] 1.6.2.2. Estabeleça prazo adequado para a realização de visitas técnicas, não restringindo-a à dia e horário fixos, tanto no intuito de inibir que os potenciais licitantes tomem conhecimento prévio do universo de concorrentes, quanto a fim de que os possíveis interessados ainda contem, após a realização da visita, com tempo hábil para a finalização de suas propostas".
} 
te, o financiamento de campanhas por atores privados seja capaz de gerar sentimentos de retribuição entre o agente público eleito e o doador. Nas palavras de Lessig, por exemplo, "todos nós reconhecemos tendência que vem do fundo de nossos ossos - ou, mais precisamente, em nosso DNA - de agir reciprocamente. Às vezes não o fazemos. O subconsciente é guiado por interações de reciprocidade tanto quando o consciente. Todos nós agimos de modo recíproco mesmo sem pensar. Nós nos curvamos àqueles que devemos obrigações, mesmo que acreditemos honestamente que não nos curvamos". No Brasil, o financiamento de campanhas foi regulado, inicialmente, pela Lei 9.504/97, que estabelecia o limite de gastos de campanha para os cargos em disputa e aos partidos políticos a obrigação de comunicar à Justiça Eleitoral os valores máximos que fariam por cada candidatura. O desrespeito a esses limites podia ocasionar multa no valor de cinco a dez vezes a quantia em excesso. Com a edição da Lei 12.034/09, e, posteriormente, da Lei 13.165/15, as regras sobre doação se tornaram mais restritas, até que, no julgamento da ADI 4650, o STF proibiu o financiamento empresarial de campanhas eleitorais.

\section{Informação}

As estratégias regulatórias baseadas em informação ou transparência buscam a divulgação de informações relevantes sobre instituições, de modo que seja possível avaliá-las ${ }^{22}$ ou alterar o comportamento de seus atores. O conceito abrange tanto a divulgação ativa de informações pelas entidades públicas (transparência ativa) - incluindo dados sobre seu funcionamento e agentes - quanto a resposta a pedidos de acesso à informação realizados por indivíduos ou entidades (transparência passiva).

Como já se adiantou acima, a estratégia de comando e controle depende de informações para efetivamente punir os agentes transgressores. ${ }^{23}$ Além disso, os mecanismos de transparência são também capazes de prevenir, indiretamente, a ocorrência de atos de corrupção. A expectativa é que, estando mais exposta a atuação administrativa, os riscos de corrupção se reduzam. Em termos da terminologia adotada pela Teoria do Principal-agente, estratégias baseadas em transparência estão à disposição para que o principal possa controlar o agente, evitando que o agente atue em seus próprios interesses ao invés de nos interesses do principal. ${ }^{24}$

A prevenção será alcançada por meio de dois mecanismos diferentes. Por um lado, há um aumento da probabilidade de que o governo irá fiscalizar determinados contratos realizados pela administração pública, como ocorre com o Programa de Sorteios Públicos realizado pela Controladoria Geral da União (CGU) conforme exploraremos na seção 3.1. Por outro, investe-se na ampliação da transparência das entidades administrativas, principalmente por meio da Lei de Acesso à Informação - analisada na seção 3.2. ${ }^{25}$ A diferença entre esses dois tipos de transparência é que, no primeiro, o governo ativamente investe na divulgação de informações ao passo que, no segundo, apenas criam-se obrigações e ambiente favorável para que terceiros possam se valer dessas informações para fiscalizar as entidades.

Diferentemente da estratégia de comando e controle, os dois mecanismos de transparência não necessariamente pressupõem a capacidade de punição do próprio Estado. Porém, dependem, por exemplo, da capacidade de eleitores - uma vez informados sobre atos ilícitos cometidos - disciplinarem políticos corruptos. ${ }^{26}$

22 LINDSTEDT, Catharina; NAURIN, Daniel. Transparency is not Enough: Making Transparency Effective in Reducing Corruption. International Political Science Review, v. 31, n. 3, p. 301-322, 2010. p. 301.

23 OLKEN, Benjamin A. Monitoring corruption: evidence from a field experiment in Indonesia. Journal of political Economy, v. 115, n. 2, p. 200-249, 2007. p. 201.

24 LINDSTEDT, Catharina; NAURIN, Daniel. Transparency is not Enough: Making Transparency Effective in Reducing Corruption. International Political Science Review, v. 31, n. 3, p. 301-322, 2010. p. 303.

25 V. ABRAMO, Claudio Weber. Acesso a informação e eficiência do Estado, Revista gov. sp, n. 2, 2004.

26 WINTERS, Matthew S; WEITZ-SHAPIRO, Rebecca. Lacking information or condoning corruption: When do voters support corrupt politicians?. Comparative Politics, v. 45, n. 4, p. 418-436. 2013; FERRAZ, Claudio; FINAN, Frederico. Electoral accountability and corruption: Evidence from the audits of local governments. The American Economic Review, v. 101, n. 4, p. 1274-1311, 2011. 
O foco é na divulgação de informações (tanto pela própria CGU quanto pela Lei de Acesso à Informação), não no estabelecimento de normas ou punições. É justamente por esse motivo que a realização de auditorias não é classificada, neste artigo, como parte da estratégia de comando e controle, isto é, como mecanismo de descoberta de ilícitos para a aplicação de sanções. O mecanismo das auditorias, tal qual realizado pelo Programa de Sorteios Públicos, tem como objetivo não apenas oferecer subsídios ao poder sancionador estatal como também disciplinar funcionários públicos por meio da revelação de informações sobre seus atos, gerando consequências reputacionais, políticas e penais. Dito de outra forma, o papel das auditorias ultrapassa possíveis constatações de ilícitos para aplicação de sanções, inclui, também, mecanismo de prevenção realizado por outros agentes públicos e privados, por meio do aumento de accountability da administração pública.

\subsection{Auditorias}

A Controladoria Geral da União (GCU) surgiu em 2003 com o objetivo de detectar a punir ilicitudes sistematicamente. Logo depois de sua criação, a CGU lançou o Programa de Sorteios Públicos, com o objetivo de aumentar a fiscalização sobre os gastos municipais de verbas repassadas pela União. Inicialmente, a CGU fez auditorias em 26 municípios escolhidos aleatoriamente e, logo em seguida, esse número aumentou para 60 municípios a cada loteria. Em fevereiro de 2015, tinha realizado 2241 auditorias em 1949 municípios, tendo auditado mais de 22 bilhões de dólares em repasses federais aos municípios. ${ }^{27}$ Uma série de estudos avaliaram, com base em diversas perspectivas, os programas de auditoria realizados pela CGU.

Em estudo realizado em 2016, Avis, Ferraz e Finan demonstraram que municípios que já passaram por auditorias no passado tiveram uma redução de $8 \%$ nos índices de corrupção. ${ }^{28}$ Além disso, esses municípios já auditados no passado têm uma probabilidade $20 \%$ maior de sofrerem sanções legais. Portanto, haveria, segundo os autores, efeitos legais disciplinadores (legal disciplining effects) decorrentes das auditorias. Isto é, prefeitos procurarão não se envolver em ilicitudes para evitar as sanções legais e custos reputacionais.

É interessante notar que, nesse modelo adotado, há um aprendizado pelos políticos. Ou seja, espera-se que a mídia local alerte prefeitos sobre a ocorrência de auditorias em municípios adjacentes, reduzindo sua probabilidade de cometer ilicitudes (spillover effect). Os resultados encontrados revelaram que um município adjacente auditado reduz a corrupção em 7,5\% quando há uma rádio AM local e em 10,4\% quando há uma televisão local.

No mesmo sentido, em estudo realizado em 2013, Zamboni e Litschig analisaram tanto processos de licitação quanto prestação de serviços do Bolsa Família e do Saúde da Família. ${ }^{29}$ Descobriram que um aumento temporário de $20 \%$ do risco de ser auditado gerou uma redução de $17 \%$ de irregularidades nos processos de licitação totais. Já sobre a prestação de serviços, não encontraram variações, de modo que uma das explicações plausíveis é de que, ao contrário das licitações - nas quais há uma exigência de prestação de contas em todas as etapas -, a prestação de serviços é mais difícil de ser avaliada, o que permite maiores oportunidades para corrupção.

Além dos riscos legais associados à descoberta de atos corruptos, as auditorias também são mecanismos que geram custos eleitorais a políticos. A explicação para esse mecanismo deve ser feita em duas etapas: (i) avaliar como eleitores se comportam quando descobrem atos de corrupção de políticos (i.e., se punirão políticos corruptos nas urnas) e, em caso positivo, (ii) verificar se agentes públicos reagem, antecipadamente,

\footnotetext{
27 AVIS, Eric; FERRAZ, Claudio; FINAN, Frederico. Do Government Audits Reduce Corruption?, Journal of Political Economy, v. 126, n. 5, p. 1912-1964, 2018; POWER, Timothy Joseph; TAYLOR, Matthew MacLeod. Corruption and democracy in Brazil: the struggle for accountability. Notre Dame: University of Notre Dame Press, 2011.

28 AVIS, Eric; FERRAZ, Claudio; FINAN, Frederico, Do Government Audits Reduce Corruption?, Journal of Political Economy, v. 126, n. 5, p. 1912-1964, 2018.

29 ZAMBONI, Yves; LITSCHIG, Stephan. Audit risk and rent extraction: Evidence from a randomized evaluation in Brazil. Universitat Pompeu Fabra, 2013.
} 
à possibilidade de punição nas urnas caso sejam flagrados em atos de corrupção, diminuindo, assim, suas práticas corruptas.

Na primeira etapa, é necessário saber como eleitores respondem à revelação de ilicitudes. Ferraz e Finan identificaram, em 2008, que, nos municípios em que as auditorias reportaram duas ou mais irregularidades, os prefeitos tiveram uma chance de reeleição reduzida em $17 \%$ se comparado aos prefeitos que não sofreram auditorias. ${ }^{30}$ Por outro lado, aqueles que foram auditados e em relação aos quais não foram descobertas irregularidades tiveram um aumento de apoio nas urnas. Ambos os resultados são ampliados no caso de presença de rádio local. A conclusão deste estudo é de que os eleitores não somente se preocupam com corrupção, mas punem ou recompensam políticos de acordo com seu desempenho ético. ${ }^{31}$

A segunda etapa corresponde à reação dos agentes públicos diante desse cenário. Comparando o desempenho de prefeitos no primeiro e segundo mandatos, Ferraz e Finan, em estudo de 2011, buscaram entender os incentivos gerados pela possibilidade de reeleição. ${ }^{32} \mathrm{O}$ resultado refere-se ao fato de que prefeitos em segundo mandato - e que, portanto, não têm oportunidade de reeleição - participam $27 \%$ mais em atos de corrupção do que aqueles reelegíveis (em primeiro mandato). Esse resultado parece demonstrar que políticos tendem a diminuir suas práticas corruptas visando evitar a punição nas urnas.

Olhando as duas etapas em conjunto, as pesquisas sugerem que tanto os eleitores estão preocupados com atos de corrupção (primeira etapa) ${ }^{33}$ quanto políticos reagirão em decorrência da possibilidade de serem punidos ou recompensados nas urnas (segunda etapa)..$^{34}$

No cenário internacional, os resultados também parecem positivos quanto à utilização de programas de auditoria. Di Tela analisou o papel do aumento de salários e das auditorias como estratégias de combate à corrupção realizadas pelo governo de Buenos Aires. ${ }^{35}$ Verificou que, nos primeiros meses após a implementação do programa, os preços pagos por produtos homogêneos para abastecer hospitais diminuíram quase $15 \%$ a partir do momento em que o governo começou a disseminar informações sobre preços. Nos meses seguintes, os valores subiram, mas, ainda assim, continuaram abaixo dos valores pagos antes da disseminação de informações.

Na Indonésia, os resultados parecem semelhantes. Em 2007, Olken testou, entre outras coisas, se a probabilidade de monitoramento pelo governo afeta a eficiência dos gastos para a realização de projetos de infraestrutura em vilas na Indonésia. ${ }^{36}$ Descobriu que, com o aumento da probabilidade de auditoria sobre os gastos de 4\% para 100\%, houve uma redução de $8 \%$ dos gastos perdidos por ineficiência ou corrupção. Uma das justificativas encontradas para a redução não ter sido maior é que, mesmo com a probabilidade de $100 \%$ de ter seus gastos auditados, a probabilidade de ser punido é muito inferior a 100\%. Não necessaria-

30 FERRAZ, Claudio; FINAN, Frederico. Exposing corrupt politicians: the effects of Brazil's publicly released audits on electoral outcomes. The Quarterly Journal of Economics, v. 123, n. 2, p. 703-745, 2008.

31 Este não é um resultado pacífico na literatura. Para a apresentação de argumentos de que, mesmo que tenha a revelação de informações sobre corrupção de políticos, a população continuaria a votar neles novamente, ver CARSON, Lindsey D; PRADO, Mariana Mota. Using institutional multiplicity to address corruption as a collective action problem: Lessons from the Brazilian case. The Quarterly Review of Economics and Finance, v. 62, p. 56-65, 2016. p. 61. Conferir também: DE FIGUEIREDO, Miguel FP; HIDALGO, F Daniel; KASAHARA, Yuri. When do voters punish corrupt politicians? Experimental evidence from Brazil, Unpublished manuscript. UC Berkeley, 2011; PEREIRA, Carlos; MELO, Marcus André. Reelecting corrupt incumbents in exchange for public goods: Rouba mas faz in Brazil. Latin American Research Review, p. 88-115, 2015.

32 FERRAZ, Claudio; FINAN, Frederico. Electoral accountability and corruption: Evidence from the audits of local governments. The American Economic Review, v. 101, n. 4, p. 1274-1311, 2011.

33 FERRAZ, Claudio; FINAN, Frederico. Electoral accountability and corruption: Evidence from the audits of local governments. The American Economic Review, v. 101, n. 4, p. 1274-1311, 2011.

34 FERRAZ, Claudio; FINAN, Frederico. Electoral accountability and corruption: Evidence from the audits of local governments. The American Economic Review, v. 101, n. 4, p. 1274-1311, 2011.

35 DI TELLA, Rafael; SCHARGRODSKY, Ernesto. The role of wages and auditing during a crackdown on corruption in the city of Buenos Aires. The Journal of Law and Economics, v. 46, n. 1, p. 269-292, 2003.

36 OLKEN, Benjamin A. Monitoring corruption: evidence from a field experiment in Indonesia. Journal of political Economy, v. 115, n. 2, p. 200-249, 2007, p. 201. 
mente serão descobertas todas as possíveis fraudes realizadas e, muitas vezes, as descobertas levam a provas, apenas, circunstanciais para a denúncia.

Por outro lado, pode ser que todos os resultados encontrados sejam, apenas, de curto prazo, de modo que os níveis de corrupção voltariam aos mesmos patamares no longo prazo. Para testar isso, foram analisadas auditorias não aleatórias em Porto Rico. ${ }^{37}$ Descobriu-se que há uma redução de $67 \%$ da corrupção em curto prazo - quando os relatórios foram divulgados antes das eleições, permitindo que os eleitores punissem ou recompensassem os políticos -, mas os resultados se dissiparam no decorrer do tempo. Com isso, quando as auditorias são não aleatórias, os resultados são apenas de curto prazo.

De todos os experimentos analisados, duas conclusões parciais parecem possíveis. A primeira é que, caso os indivíduos tenham a possibilidade de punir ou recompensar políticos pela descoberta ou não de atos de corrupção, mecanismos de transparência como as auditorias são meios efetivos de controlar agentes corruptos. As auditorias, apesar de serem mecanismos de transparência per se, têm seus resultados muitas vezes amplificados por outros mecanismos de informação, como a presença de mídia local. Essas mídias servem para aumentar a accountability de políticos ou para informar políticos sobre a efetividade dos programas anticorrupção que ocorrem ao seu redor, gerando um spillover effect. A segunda conclusão é que o sucesso das auditorias depende de serem aleatórias e com probabilidades elevadas de identificar atos ilícitos, como ocorreu no Brasil durante o Programa de Sorteios Públicos, sob o risco de gerarem efeitos, apenas, de curto prazo como aqueles vivenciados em Porto Rico.

\subsection{Acesso à Informação}

Para além da realização de auditorias promovidas pelo governo, é possível aumentar o nível de transparência por meio da disponibilização de dados para a população. Espera-se que as pessoas tenham acesso tanto a informações sobre o próprio funcionamento das entidades como sobre a atuação dos agentes públicos envolvidos e, com isso, promovam maior fiscalização popular.

O exemplo mais significativo é o da Lei $12.527 / 11^{38}$, relativa à garantia ao acesso à informação previsto no inciso XXXIII do art. $5^{\circ}$, no inciso II do $\int 3^{\circ}$ do art. 37 e no $₫ 2^{\circ}$ do art. 216 da Constituição Federal. ${ }^{39} \mathrm{~A}$ lei investe tanto na transparência passiva - dado que, em seu art. $3^{\circ}$, estabelece a obrigatoriedade de divulgação de informações de interesse público, independentemente de solicitações e a observância da publicidade como preceito geral e do sigilo como exceção - quanto na transparência ativa, que se dá por meio do pedido de acesso à informação, que pode ser apresentado por qualquer interessado, por qualquer meio legítimo, devendo, apenas, conter a identificação do requerente e a identificação da informação requerida. Para garantir a eficácia da transparência passiva, prevê sanções disciplinares aos responsáveis pela recusa injustificada de concessão de informações, bem como os recursos disponíveis à parte que tenha o seu pedido negado. Há, ainda, previsões para abertura de sindicâncias no caso de extravio de informações solicitadas, circunstância que é comum no caso de documentos que possam comprovar a existência de esquemas de corrupção.

Esta é uma lei que foca na diminuição do custo de obtenção de informações, dado que faz com que o ônus de coleta de informações seja atribuído com mais peso às entidades públicas. E, mais do que isso, a lei busca garantir que a precisão e a utilidade da informação sejam facilmente monitoradas e seu enforcement

\footnotetext{
37 BOBONIS, Gustavo J; FUERTES, Luis Cámara R; SCHWABE, Rainer. Monitoring Corruptible Politicians. The American Economic Review, v. 106, n. 8, p. 2371-2405, 2016.

38 Antes do advento da lei de acesso à informação, este direito estava previsto em algumas legislações esparsas sobre responsabilidade fiscal, proteção do meio ambiente etc. Para um histórico da discussão, tramitação e aprovação desta lei, v. PAES, Eneida Bastos. A construção da Lei de Acesso à Informação Pública no Brasil: desafios na implementação de seus princípios. Revista do Serviço Público, v. 62, n. 4, p. 407-423, 2014.

39 A lei afeta praticamente todas as instituições públicas e mesmo instituições privadas sem fins lucrativos que recebam, para realização de ações de interesse público, recursos públicos diretamente do orçamento ou mediante subvenções sociais, contrato de gestão, termo de parceria, convênios, acordo, ajustes ou outros instrumentos congêneres.
} 
tenha custos aceitáveis. ${ }^{40}$

Para além da edição de uma lei geral de acesso à informação, há leis esparsas que buscam aumentar o nível de transparência de atividades governamentais ou atividades que podem impactar a sociedade. Uma dessas leis é a Lei 8.666/93, que permite em diversos dos seus dispositivos o acesso do público aos documentos da licitação, o que inclui a garantia de que a licitação é um procedimento público, estando acessíveis a todos os atos de seus procedimentos. $\mathrm{E}$, mais do que isso, garante aos cidadãos o acesso a quantitativos das obras e preços unitários de determinada obra executada.

Já a Lei de Responsabilidade Fiscal contribui para ampliar a transparência no manejo das contas e dos orçamentos públicos. ${ }^{41}$ Determina, por exemplo, a transparência de planos, orçamentos e leis de diretrizes orçamentárias, das prestações de conta e do respectivo parecer prévio, entre outros documentos. Prevê-se, ainda, a participação popular e a realização de audiências públicas durante os processos de elaboração e de discussão dos planos, bem como das leis de diretrizes orçamentárias e orçamentos.

De modo geral, essas leis buscam aumentar os custos que agentes públicos teriam ao se envolver em atos de corrupção, podendo inibir sua ocorrência, dado que há mais informações disponíveis ao público que, possivelmente, poderão ser analisadas e gerarão a descoberta de ilícitos. Por exemplo, caso haja fraude em uma licitação, os atores terão um custo relativamente alto para tentar escondê-la em meio aos documentos que serão de acesso público. Para avaliar essa ideia de aumento de custos, uma série de estudos investiga possíveis correlações entre a presença de transparência e diminuição de corrupção. Resta saber se, de fato, há benefícios em investir nesses mecanismos de transparência, avaliando seus prós e contras.

Em estudo comparativo sobre a percepção de corrupção entre países em relação ao nível de divulgação de informações de parlamentares, percebeu-se que menos da metade dos países que têm a obrigatoriedade de disponibilização de dados o fazem para o público geral. ${ }^{42}$ Normalmente essa informação é divulgada apenas para entidades específicas, como órgãos de monitoramento. Como é a disponibilização de dados para o público em geral que está associada à percepção de diminuição de corrupção, a maior parte dos países tem índices altos de desconfiança da população. Resultado similar é encontrado por outro estudo, ao comparar a disponibilização pública com aquela voltada para determinados órgãos de controle. ${ }^{43}$ Por outro lado, análise realizada em 2012 por Samia Costa revelou que a presença de leis de acesso à informação não diminui a percepção de corrupção, inclusive gera o efeito contrário - de aumento da percepção - nos primeiros quatro anos de implementação. ${ }^{44}$ Os resultados desses três estudos são normalmente criticados pela literatura por analisarem, apenas, a percepção sobre a corrupção, o que não necessariamente reflete os índices reais de corrupção em um país. ${ }^{45}$

Outros estudos, utilizando metodologias mais confiáveis, encontram correlações entre o aumento de transparência e diminuição de corrupção. Em experimento sobre o acesso a cartões de alimentação que dão acesso a serviços de assistência social à população mais pobre de moradores da favela de Nova Délhi,

\footnotetext{
40 BALDWIN, Robert; CAVE, Martin; LODGE, Martin. Understanding regulation: theory, strategy, and practice. New York: Oxford University Press, 2012.

41 FIGUEIREDO, Marcelo. "A lei de responsabilidade fiscal - notas essenciais e alguns aspectos da improbidade administrativa". Revista Diálogo Jurídico, Salvador, ano I, v. I, n. 9, dez. 2001. Disponível em http://www.direitopublico.com.br. Acesso em: 08 jan. 2017.

42 DJANKOV, Simeon et al. Disclosure by politicians. American Economic Journal: Applied Economics, v. 2, n. 2, p. 179-209, 2010.

43 GOKCEKUS, Omer; MUKHERJEE, Ranjana. Officials’ Asset Declaration Laws: Do They Prevent Corruption?, Global Corruption Report, 2006.

${ }_{44}$ COSTA, Samia. Do freedom of information laws decrease corruption?. The Journal of Law, Economics, \& Organization, v. 29, n. 6, p. 1317-1343, 2012.

45 Sobre possíveis críticas a estes estudos, ver TAYLOR, Matthew M. Veto and voice in the courts: policy implications of institutional design in the Brazilian judiciary. Comparative Politics, p. 337-355, 2006; JOHNSØN, Jesper; TAXELL, Nils; ZAUM, Dominik. Mapping evidence gaps in anti-corruption: Assessing the state of the operationally relevant evidence on donors' actions and approaches to reducing corruption, U4 Issue, v. 2012, n. 7, 2012; e nota de rodapé no 4 de REINIKKA, Ritva; SVENSSON, Jakob. The power of information: Evidence from a newspaper campaign to reduce capture. US: World Bank Publications, 2004.
} 
demonstrou-se que a adoção de Leis de Acesso à Informação são quase tão efetivas quanto subornos para ajudar os mais pobres a terem acesso a serviços públicos básicos. ${ }^{46} \mathrm{Ou}$ seja, informação pode ser utilizada como substituto à riqueza nos casos em que cidadãos pobres desejam obter serviços de um governo corrupto ou ineficiente.

Em outro experimento sobre a Índia, os pesquisadores deram informações aos eleitores sobre políticos e o resultado foi que o acesso à informação é utilizado pela população como um mecanismo para conseguir a eleição de candidatos mais responsivos. ${ }^{47}$ Outro resultado foi a diminuição da compra de votos em dinheiro pois, como a população tinha informações para votar em candidatos que efetivamente melhorariam suas condições de vida - já que tinham acesso a dados como de sua performance passada -, o valor do voto aumentou e, consequentemente, a quantidade de compra diminuiu.

Já em Uganda, o governo passou a disponibilizar informações sobre a distribuição de verbas centrais destinadas a escolas, de modo que os diretores das escolas destinatárias dos programas de financiamento tinham maior capacidade de monitoramento. A partir da divulgação e acesso público dessas informações, a quantidade de fundos desviados diminuiu drasticamente, revelando que o acesso público à informação é uma estratégia poderosa para diminuir captura local. ${ }^{48}$

Apesar dos resultados positivos encontrados nestes estudos, a confiança em mecanismos de transparência normalmente é sujeita a uma série de críticas. O primeiro problema - custo de verificação - é recorrente no Brasil, onde parte dos pedidos de acesso à informação são negados sem que haja justificativas legítimas. ${ }^{49}$ Em recente avaliação da responsividade de órgão públicos brasileiros, os dados agregados obtidos mostraram uma taxa de resposta de $55 \%$ e $24 \%$ de taxa de precisão, ou seja, muitos pedidos de acesso à informação são sequer respondidos e, quando respondidos, não o são de maneira satisfatória. ${ }^{50}$ Além de cidadãos muitas das vezes sequer conseguirem enviar pedidos de informação - "porque muitos órgãos públicos não oferecem ferramentas adequadas para que os cidadãos enviem questionamentos" ${ }^{51}$-, os órgãos públicos não respondem ou enviam informações que não são adequadas para avaliar o correto funcionamento da administração pública. Normalmente, esse resultado é devido à ausência de sanção aos entes públicos que não cumprirem a Lei de Acesso à Informação, como "ainda mais se tratando de órgãos autônomos dentro do Poder Legislativo, que é o caso dos Tribunais de Contas". ${ }^{52}$

O segundo problema é a necessidade de regular especificamente o que é uma informação de qualida-

\footnotetext{
46 PEISAKHIN, Leonid; PINTO, Paul. Is transparency an effective anti-corruption strategy? Evidence from a field experiment in India, Regulation \& Governance, v. 4, n. 3, p. 261-280, 2010.

47 BANERJEE, Abhijit et al. Do informed voters make better choices? Experimental evidence from urban India. Unpublished manuscript, 2011.

48 REINIKKA, Ritva; SVENSSON, Jakob. The power of information: Evidence from a newspaper campaign to reduce capture. US: World Bank Publications, 2004.

49 Esse problema é tratado na literatura regulatória como um custo de verificação das informações: “[...] where information regulation is employed there is always a danger that the information will be inaccurate and unjustifiable claims made. Policing of the quality of information will, accordingly, be necessary. This increases the costs of information-based regulatory regimes". BALDWIN, Robert; CAVE, Martin; LODGE, Martin. Understanding regulation: theory, strategy, and practice. New York: Oxford University Press, 2012. p. 120.

50 OLIVEIRA, Marina Gandra Camargo de Barros; RODRIGUES, Karina Furtado. Transparência em contas públicas no âmbito local no Brasil. In: MOHALLEM, Michael Freitas; RAGAZZO, Carlos Emmanuel Joppert (org.). Diagnóstico institucional: primeiros passos para um plano nacional anticorrupção. Rio de Janeiro: Escola de Direito do Rio de Janeiro da Fundação Getulio Vargas, 2017. p. 116-121.

51 OLIVEIRA, Marina Gandra Camargo de Barros; RODRIGUES, Karina Furtado. Transparência em contas públicas no âmbito local no Brasil. In: MOHALLEM, Michael Freitas; RAGAZZO, Carlos Emmanuel Joppert (org.). Diagnóstico institucional: primeiros passos para um plano nacional anticorrupção. Rio de Janeiro: Escola de Direito do Rio de Janeiro da Fundação Getulio Vargas, 2017. p. 116.

52 OLIVEIRA, Marina Gandra Camargo de Barros; RODRIGUES, Karina Furtado. Transparência em contas públicas no âmbito local no Brasil. In: MOHALLEM, Michael Freitas; RAGAZZO, Carlos Emmanuel Joppert (org.). Diagnóstico institucional: primeiros passos para um plano nacional anticorrupção. Rio de Janeiro: Escola de Direito do Rio de Janeiro da Fundação Getulio Vargas, 2017. p. 121.
} 
de - que se assemelha muito aos problemas já discutidos sobre o estabelecimento de standards por meio de estratégias de comando e controle. Em alguns casos, não haverá um standard regulando a informação, de modo que a transparência poderá ser realizada de uma forma que não ajude a população a monitorar as atividades administrativas. Assim como ocorre em direito do consumidor, Baldwin exemplifica que "'pode causar câncer' é uma frase que revela pouco sobre a magnitude de quaisquer riscos de câncer que podem ser causados pela utilização de um determinado produto" - raciocínio este que pode ser aplicado também para casos de corrupção.

O terceiro está associado ao tratamento das informações..$^{53}$ Mesmo que todas as informações estejam disponíveis, provavelmente a maior parte não atingirá uma ampla audiência simplesmente porque é de interesse apenas de uma parte da população. Para além disso, o tratamento das informações é custoso e não necessariamente é possível concluir que houve algum ato de corrupção mesmo diante da análise de todos os dados, o que é agravado por vieses e heurísticas a que os seres humanos estão submetidos - por exemplo, diante de evidências favoráveis e contrárias a uma posição, seres humanos tendem a dar mais valor àquelas informações que sustentam suas opiniões pré-concebidas, por meio de viés conhecido como viés de confirmação. ${ }^{54}$

O quarto obstáculo é a capacidade de a população acessar e processar as informações. Mesmo que os custos de coleta de informações sejam baixos, a capacidade de analisar o conteúdo é essencial para que sejam tomadas medidas. A habilidade de compreensão dessas informações somente será realizada, portanto, dependendo do nível de educação da população de determinado local. Nas palavras de Lindstedt e Naurin, "quanto maior o nível de educação, pode-se assumir, maior será a capacidade das pessoas tanto para acessar quanto para processar informações da mídia e de dados públicos e, consequentemente, maiores as chances para a publicidade [ser bem-sucedida]".

Quinto, a mídia é o melhor mecanismo de mediação, simplificando as informações e entregando-as ao público. No entanto, pode ser que a própria mídia seja corrupta ou não se sinta confortável para divulgar as informações necessárias para o monitoramento pela população. ${ }^{55} \mathrm{Uma}$ das formas de evitar vieses causados pela mídia é a dispersão desse papel com a população, como vem ocorrendo com a automatização de detecção de ilegalidades em notas fiscais apresentadas por políticos. ${ }^{56}$

A existência desses cinco obstáculos faz com que sejam necessárias algumas qualificações para que transparência seja eficiente no combate à corrupção. A simples transparência não é suficiente para a redução da corrupção, é necessária a habilidade de processar a informação e a criação de incentivos corretos para agir de acordo com a informação processada $\cdot{ }^{57} \mathrm{Ou}$, de outra forma, o acesso à informação não garante que sejam entendidas pelo público destinatário para que exerçam o monitoramento da administração pública; deve haver a capacidade de compreensão da informação e meios de punição (accountability) de atores que desviem do comportamento adequado.

Garantir a liberdade de imprensa é um primeiro passo para a efetividade da transparência. Há uma série de estudos que a associam existência de uma mídia livre a uma diminuição nos níveis de corrupção a uma diminuição da corrupção. Há estudo que afirma que, se a Nigéria aumentasse seus níveis de liberdade de imprensa para os níveis da Noruega, a consequência seria a redução dos níveis de corrupção nigerianos aos níveis dos países do Leste Europeu. ${ }^{58}$ Contudo, esta é uma afirmação controvertida, cujo contra-argumento

53 LINDSTEDT, Catharina; NAURIN, Daniel. Transparency is not Enough: Making Transparency Effective in Reducing Corruption. International Political Science Review, v. 31, n. 3, p. 301-322, 2010, p. 304.

54 KAHNEMAN, Daniel. Thinking, fast and slow. New York: Macmillan, 2011. cap. 25.

55 KAHNEMAN, Daniel. Thinking, fast and slow. New York: Macmillan, 2011. cap. 25.

56 Cf. iniciativa conhecida como Rosie da Serenata, disponível em: https://motherboard.vice.com/pt_br/article/robos-contra-acorrupcao https://twitter.com/RosieDaSerenata. Acesso em 27 de setembro de 2018.

57 KOLSTAD, Ivar; WIIG, Arne. Is transparency the key to reducing corruption in resource-rich countries? World development, v. 37 , n. 3, p. 521-532, 2009.

58 BRUNETTI, Aymo; WEDER, Beatrice. A free press is bad news for corruption. Journal of Public Economics, v. 87, n. 7, p. 1801- 
refere-se ao fato de que se devem incluir, também, níveis educacionais e eleições livres e justas. ${ }^{59}$

Outra forma, indireta, de aumentar o contato popular com as informações decorrentes da transparência é por meio de tecnologias da informação e comunicação (ITCs) - normalmente mídias sociais e do chamado e-government. Agências federais norte-americanas, por exemplo, têm utilizado mídias sociais, blogs, sites e outras mídias para disseminar informação e se comunicar com o público. Já as Filipinas e o Chile desenvolveram sistemas de licitação eletrônica (e-procurement), permitindo ao público realizar o monitoramento ativo das licitações e processos de contratação governamentais. ${ }^{60}$ Há evidências de que essa estratégia efetivamente diminui níveis de corrupção. ${ }^{61}$

Apesar de o investimento em transparência parecer bastante promissor, alguns estudos a correlacionam a efeitos negativos, incluindo o próprio aumento da corrupção em determinados contextos. Um primeiro estudo, realizado por Mehmet Bac em 2001, argumenta que o aumento da transparência não necessariamente resulta em menores níveis de corrupção. ${ }^{62}$ Maior transparência significa que condutas ilícitas serão mais facilmente identificadas, mas também aumentará a quantidade de informações sobre os funcionários com os quais corruptores devem se conectar para efetuar acordos ilícitos. Em algumas situações pontuais, os efeitos negativos de identificação de oficiais corruptos podem ser maiores do que o efeito de desencorajamento de agentes públicos. Entretanto, nos casos em que houver aumentos consideráveis de transparência, o efeito de detecção superará o efeito de facilitação de conexões (pela identificação de tomadores de decisão "chave").

Já outro estudo, realizado por Andrea Prat em 2003, analisa a proposição de que, em certas circunstâncias, revelar informações sobre o agente faz com que seus interesses se tornem menos alinhados aos do principal. ${ }^{63}$ Em seu modelo, a transparência sobre as ações tomadas por agentes públicos pode gerar efeitos negativos, ao passo que aquela sobre as consequências das ações pode ser benéfica. Isso ocorre porque o agente público pode ter informações privadas que podem fazer com que o público veja aquela ação como negativa. Com isso, não se utilizará dessas informações que poderiam ser boas para o interesse público com medo de sofrer possíveis retaliações do público que não sabe da existência dessas informações privadas.

Por fim, há estudo que argumenta que a cobertura da mídia pode, em contextos específicos, diminuir a qualidade de políticos, já que bons políticos não aceitariam se submeter ao escrutínio público dos candidatos promovido pela imprensa. ${ }^{64}$ Esse efeito pode ser prejudicial quando não compensado pelos benefícios associados à maior transparência (screening effect).

\section{Incentivos}

As estratégias regulatórias baseadas em incentivos buscam conformar a atuação dos agentes - públicos e regulados - por meio de benefícios ou constrangimentos atrelados a cada padrão de conduta. No modelo de principal-agente, busca-se modificar a análise custo-benefício do agente para que suas condutas e interesses se alinhem aos do principal (sociedade).

$1824,2003$.

59 Essa é a afirmação de Lindstedt e Naurin, ao falarem que se acrescentasse à equação níveis educacionais e eleições livres e justas, o resultado seria diferente (LINDSTEDT, Catharina; NAURIN, Daniel. Transparency is not Enough: Making Transparency Effective in Reducing Corruption. International Political Science Review, v. 31, n. 3, p. 301-322, 2010).

60 CARLO BERTOT, John; JAEGER, Paul T; GRIMES, Justin M. Promoting transparency and accountability through ICTs, social media, and collaborative e-government. Transforming Government: People, Process and Policy, v. 6, n. 1, p. 78-91, 2012.

${ }_{61}$ ANDERSEN, Thomas Barnebeck. E-Government as an anti-corruption strategy. Information Economics and Policy, v. 21, n. 3, p. 201-210, 2009.

62 BAC, Mehmet. Corruption, connections and transparency: Does a better screen imply a better scene? Public Choice, v. 107, n. 1-2, p. 87-96, 2001.

63 PRAT, Andrea. The wrong kind of transparency. 2003.

64 SUTTER, Daniel. Media scrutiny and the quality of public officials. Public Choice, v. 129, n. 1-2, p. 25-40, 2006. 
A dificuldade em implementar esse tipo de estratégia está na análise de cada comportamento específico adotado pelos agentes em todos os contextos. Isso faz com que alguns estudos não encontrem correlação entre o incentivo proposto e a diminuição da corrupção e outros, alternando alguns fatores específicos, encontrem fortes correlações. Por exemplo, ao estudar impactos da leniência, Spagnolo (2004) critica estudos anteriores por adotarem modelos que se distanciam da realidade. ${ }^{65}$ Este é o caso de Apesteguia, Dufwenberg e Selten (2007), ao utilizarem um modelo no qual os atores não podem aprender enquanto jogam repetidamente, ou seja, as situações são apresentadas como um jogo de uma só rodada. ${ }^{66}$

Alguns dos possíveis incentivos parecem ser bem estudados pela literatura estrangeira. Com pequenas modificações, poderiam ser implementados na administração pública brasileira. Analisaremos mais profundamente duas estratégias: aumento de salários e acordos de leniência/delação premiada.

\subsection{Aumento de salários}

É intuitivo pensar no aumento do salário de funcionários públicos como um mecanismo de diminuição dos níveis de corrupção na administração pública, já que modificaria a análise custo-benefício de participar de atos de corrupção. Becker e Stigler foram os primeiros a mostrar que altos salários, associados ao monitoramento, poderiam ser utilizados para combater atos ilícitos em um cenário em que o Estado não é capaz de fiscalizar de modo perfeito a atuação dos agentes públicos. ${ }^{67}$ Nesse caso, o aumento salarial deve ser "em quantidade que seja inversamente proporcional à probabilidade de detecção e diretamente proporcional ao tamanho dos subornos e de outros benefícios obtidos por práticas ilícitas". O mecanismo de incentivos por trás dessa proposta é de que a diferença nos salários impõe "um custo de demissão igual ao valor presente da diferença entre o fluxo de ganhos futuros no caso de cumprimento das leis e em outros empregos. Esse custo pode mais do que compensar o ganho com a infração".

Contudo, alguns estudos posteriores tentaram encontrar relações entre aumento de salários e variação nos níveis de corrupção, sem encontrar correlações significativas. ${ }^{68}$ Esses estudos são criticados por utilizarem dados agregados e dados obtidos por meio de questionários, por não considerarem que uma série de fatores podem levar ao resultado encontrado - por exemplo, Becker e Stigler adicionam requisitos mínimos de auditorias ou monitoramento para que haja diminuição de corrupção ${ }^{69}$ - e por não considerarem a direção da relação de causalidade. ${ }^{70}$

Com isso, outros estudos tentaram medir a eficácia da estratégia de aumento de salários sem incorrer nos mesmos erros que os anteriores. A intuição a ser testada se baseia em, ao menos, três mecanismos de incentivos morais ou econômicos. ${ }^{71}$

O primeiro mecanismo é de que funcionários valorizam seus salários proporcionalmente ao seu rendimento. Quanto maior o ganho decorrente da remuneração lícita, maior será a perda em caso de demissão

65 SPAGNOLO, Giancarlo. Divide et impera: Optimal leniency programs CEPR Discussion paper n. 4840, , p. 8-9, 2004.

${ }^{6}$ APESTEGUIA, Jose; DUFWENBERG, Martin; SELTEN, Reinhard. Blowing the whistle. Economic Theory, v. 31, n. 1, p. 143166, 2007.

${ }^{67}$ BECKER, Gary S; STIGLER, George J. Law enforcement, malfeasance, and compensation of enforcers. The Journal of Legal Studies, v. 3, n. 1, p. 1-18, 1974.

68 RAUCH, James E; EVANS, Peter B. Bureaucratic structure and bureaucratic performance in less developed countries. Journal of public economics, v. 75, n. 1, p. 49-71, 2000; TREISMAN, Daniel. The causes of corruption: a cross-national study. Journal of public economics, v. 76, n. 3, p. 399-457, 2000.

69 BECKER, Gary S; STIGLER, George J. Law enforcement, malfeasance, and compensation of enforcers. The Journal of Legal Studies, v. 3, n. 1, p. 1-18, 1974.

70 DI TELLA, Rafael; SCHARGRODSKY, Ernesto. The role of wages and auditing during a crackdown on corruption in the city of Buenos Aires. The Journal of Law and Economics, v. 46, n. 1, p. 269-292, 2003. p. 270-271; SVENSSON, Jakob. Eight questions about corruption. The Journal of Economic Perspectives, v. 19, n. 3, p. 19-42, 2005. p. 32-33.

${ }^{71}$ ABBINK, Klaus. Fair salaries and the moral costs of corruption. Bonn Econ Discussion Papers, 2000. 
ou exoneração. ${ }^{72}$ Sob o ponto de vista de psicologia comportamental, esse argumento pode ser interpretado também como um viés de aversão à perda. ${ }^{73}$ Dito de outra forma, talvez os agentes não estejam dispostos a arriscar perder seus salários (i.e., serem demitidos) por uma expectativa de obter algumas vantagens econômicas no curto prazo.

Segundo, baixos salários podem fazer com que a qualidade dos gestores públicos diminua. Apenas aqueles menos qualificados ou desonestos aceitariam essa remuneração, tendo em vista não serem suficientemente qualificados para a iniciativa privada ou esperarem receber valores além da remuneração lícita. ${ }^{74} \mathrm{Ul}$ Haque e Sahay demonstram que o aumento de salários pode ser útil para atrair pessoas qualificadas para atuar no setor público, de modo a ajudar a transformar as instituições públicas rudimentares de países em desenvolvimento em instituições que se assemelhem àquelas de mercado. Para isso, os autores modelam o problema em torno da premissa de que a evasão fiscal de agentes particulares ocorrerá se os sistemas de monitoramento forem fracos e se as penalidades foram baixas - isto é, quando os arranjos institucionais forem fracos. Assim, os autores demonstram que aumentar os salários dos auditores fiscais diminui a evasão fiscal desde que este aumento de salário seja acompanhado por outras medidas de monitoramento e adequação das penalidades. ${ }^{75}$

O terceiro trata sobre os custos morais da corrupção. Em situações nas quais os agentes públicos recebem salários baixos, é moralmente menos repreensível que aceitem subornos. ${ }^{76}$ Essa hipótese foi testada por Abbink em um experimento no qual indivíduos representando empresas tinham a opção de subornar agentes públicos e de escolher o valor do suborno, em troca de algum favorecimento monetário. ${ }^{77}$ Na rodada seguinte, o funcionário público poderia escolher se aceitava ou não o suborno (e o valor oferecido). Alternando, apenas, o salário relativo entre a empresa e o agente público, o autor não encontra nenhuma variação significativa que comprove que "altos salários de funcionários públicos levem a menos corrupção por considerações de justiça". ${ }^{78}$ Por outro lado, Barr, Lindelow e Serneels compreenderam que a corrupção na forma de apropriação de recursos públicos é menos provável de ocorrer nos casos em que os gestores públicos tiverem maiores salários - mas, assim como descoberto por Van Rijckeghem e Weder, ${ }^{79}$ o efeito é pequeno, uma vez que é necessário um aumento muito grande do salário para gerar alterações no nível de expropriação de recursos. ${ }^{80}$

Apesar de os resultados apresentados pela literatura não provarem integralmente existência dos três incentivos morais ou econômicos supracitados para aceitar subornos, a tese central de que o aumento de salários pode reduzir corrupção - desde que presentes algumas especificações - foi suficientemente demonstrada. A partir desta constatação, é possível pensar em possíveis estratégias para diminuir o nível de corrupção na relação entre agentes públicos e particulares. Escolher a melhor estratégia significa estabelecer um equilíbrio em que se busque dispender o menor valor possível que gere a diminuição pretendida nos ní-

72 BESLEY, Timothy; MCLAREN, John. Taxes and bribery: the role of wage incentives. The economic journal, v. 103, n. 416, p. 119141, 1993; VAN RIJCKEGHEM, Caroline; WEDER, Beatrice. Bureaucratic corruption and the rate of temptation: do wages in the civil service affect corruption, and by how much? Journal of development economics, v. 65, n. 2, p. 307-331, 2001.

73 TVERSKY, Amos; KAHNEMAN, Daniel. Advances in prospect theory: Cumulative representation of uncertainty. Journal of Risk and uncertainty, v. 5, n. 4, p. 297-323, 1992.

74 BESLEY, Timothy; MCLAREN, John. Taxes and bribery: the role of wage incentives. The economic journal, v. 103, n. 416, p. 119141, 1993; KLITGAARD, Robert. Incentive myopia, World Development, v. 17, n. 4, p. 447-459, 1989; HAQUE, Nadeem Ul; SAHAY, Ratna. Do government wage cuts close budget deficits? Costs of corruption. Staff Papers, v. 43, n. 4, p. 754-778, 1996.

75 HAQUE, Nadeem Ul; SAHAY, Ratna. Do government wage cuts close budget deficits? Costs of corruption. Staff Papers, v. 43, n. 4, p. 754-778, 1996.

76 ROSE-ACKERMAN, Susan. The economics of corruption. Journal of public economics, v. 4, n. 2, p. 187-203, 1975.

77 ABBINK, Klaus. Fair salaries and the moral costs of corruption. Bonn Econ Discussion Papers, 2000.

78 Tradução livre. No original: "high salaries of public officials lead to less corruption through fairness considerations" (ABBINK, Klaus. Fair salaries and the moral costs of corruption. Bonn Econ Discussion Papers, 2000, p. 4).

79 VAN RIJCKEGHEM, Caroline; WEDER, Beatrice. Bureaucratic corruption and the rate of temptation: do wages in the civil service affect corruption, and by how much? Journal of development economics, v. 65, n. 2, p. 307-331, 2001.

80 BARR, Abigail; LINDELOW, Magnus; SERNEELS, Pieter M. To serve the community or oneself: the public servant's dilemma. World Bank Policy Research working paper n. WPS 3187, 2004. 
veis de corrupção. O pressuposto é de que nem sempre a destinação maior de recursos para um setor gerará, necessariamente, uma melhora na prestação do serviço.

A literatura parece convergir para o fato de que, dados alguns requisitos institucionais, o aumento de salários é uma estratégia regulatória capaz de gerar incentivos para a diminuição da corrupção. Svensson ${ }^{81}$ não recomenda sua utilização para países pobres em desenvolvimento porque provavelmente faltaria um terceiro responsável por garantir o seu cumprimento (third-party enforcement) assumido por Becker e Stigler ${ }^{82}$ ou faltaria o monitoramento pressuposto por Besley e McLaren. ${ }^{83}$

Essa estratégia, mesmo que seja considerada adequada para o caso brasileiro, tem de considerar o custo-benefício incorrido. Apesar das críticas sofridas, Van Rijckeghem e Weder demonstram que a estratégia de aumento de salários gera efeitos pequenos. Com um aumento de $200 \%$ nos salários, os autores preveem uma diminuição de apenas $30 \%$ dos valores expropriados. ${ }^{84}$

\subsection{WhistleBlowing e Acordos de leniência}

Outra estratégia regulatória baseada em incentivos é o desenho de acordos de leniência de modo a maximizar o surgimento de whistleblowers. ${ }^{85} \mathrm{Na}$ perspectiva de principal-agente, o objetivo do regulador consiste em criar um ambiente no qual os incentivos das partes - agente público e empresa, empresas cartelizadas etc. - sejam opostos. ${ }^{86}$ Busca-se que se aproximem ao máximo de uma situação de jogo conhecida como Dilema dos Prisioneiros. Essa estratégia regulatória é adequada para as situações nas quais há organizações com múltiplos agentes realizando práticas ilícitas, tais como corrupção, auditor-manager collusion (colusão entre auditor e administrador) e crimes corporativos em geral. ${ }^{87}$ É também uma estratégia regulatória considerada second-best, uma vez que, se as autoridades concorrenciais tivessem recursos suficientes para impedir a prática de condutas anticompetitivas, não haveria a necessidade de introduzir programas de leniência. ${ }^{88}$

A leniência é uma estratégia adotada no âmbito da autoridade concorrencial - no Brasil, pelo Conselho Administrativo de Defesa da Concorrência (CADE) - como mecanismo de reduzir ou isentar de pena um agente participante de condutas anticompetitivas (e.g., formação de cartel) que resolva cooperar com a autoridade e denunciar os outros participantes. Assim, a leniência se diferencia de colaborações premiadas pelo fato de ser uma estratégia ex ante, geral e pública. O agente corrupto é incentivado a denunciar os integrantes do acordo antes mesmo de ter sido detectado, sendo encorajado a se auto incriminar. Aplica-se a quaisquer pessoas que estejam enquadradas dentre as possibilidades legais. E, por fim, trata-se uma política codificada, automática e com campanhas de publicidade. ${ }^{89}$

A literatura sobre acordos de leniência no combate à cartelização enfatiza a necessidade da generalidade e da

81 SVENSSON, Jakob. Eight questions about corruption. The Journal of Economic Perspectives, v. 19, n. 3, p. 19-42, 2005. p. 33.

82 BECKER, Gary S; STIGLER, George J. Law enforcement, malfeasance, and compensation of enforcers. The Journal of Legal Studies, v. 3, n. 1, p. 1-18, 1974.

83 BESLEY, Timothy; MCLAREN, John. Taxes and bribery: the role of wage incentives. The economic journal, v. 103, n. 416, p. 119141, 1993; DI TELLA, Rafael; SCHARGRODSKY, Ernesto. The role of wages and auditing during a crackdown on corruption in the city of Buenos Aires. The Journal of Law and Economics, v. 46, n. 1, p. 269-292, 2003.

84 VAN RIJCKEGHEM, Caroline; WEDER, Beatrice. Bureaucratic corruption and the rate of temptation: do wages in the civil service affect corruption, and by how much? Journal of development economics, v. 65, n. 2, p. 307-331, 2001.

85 Uma definição precisa para whistle blowing é um "act of disclosing information in the public interest" SCHIKORA, Jan Theodor. Bringing good and bad whistle-blowers to the lab. University of Munich: Munich discussion paper, 2011.

86 BUCCIROSSI, Paolo; SPAGNOLO, Giancarlo. Leniency policies and illegal transactions. Journal of Public Economics, v. 90 , n. 6, p. 1281-1297, 2006. p. 1282.

87 SPAGNOLO, Giancarlo. Leniency and whistleblowers in antitrust. In: BUCCIROSSI, Paolo (org.). Handbook of Antitrust Economics. Cambridge: MIT Press, 2006. p. 262.

88 SPAGNOLO, Giancarlo. Leniency and whistleblowers in antitrust. In: BUCCIROSSI, Paolo (org.). Handbook of Antitrust Economics. Cambridge: MIT Press, 2006. p. 272.

89 Sobre a importância de a leniência promover ex ante deterrence, ver SPAGNOLO, Giancarlo. Leniency and whistleblowers in antitrust. In: BUCCIROSSI, Paolo (org.). Handbook of Antitrust Economics. Cambridge: MIT Press, 2006. p. 264-265. 
publicidade para que o instituto seja efetivo, já que promovem uma institucionalização e previsibilidade. Agentes somente se submeterão ao programa de leniência caso tenham certeza de quais serão as consequências. ${ }^{90}$

A leniência também se diferencia do modelo tradicional de symmetric whistleblowing. Tanto a empresa quanto o agente público podem denunciar (blow the whistle) em qualquer estágio do jogo, ou seja, após a tentativa de demandar suborno ou após a decisão do burocrata de reciprocar ou não. As consequências são iguais ou parecidas para ambos independentemente de quem tenha denunciado.

O symmetric whistleblowing pode gerar uma série de efeitos negativos para a sociedade. Acordos ilícitos (como cartéis, por exemplo) não podem ser levados às cortes para garantir seu cumprimento. Como a relação de suborno envolve um agente privado oferecendo dinheiro para o agente público em troca de determinadas vantagens, a relação pode ser dividida em duas fases. Na primeira, o agente público aceita ou não o suborno e, na segunda, decide se irá ou não realizar sua parte no acordo ilícito. Ocorre que a possibilidade de denunciar (blow the whistle) pode fazer com que o empresário possa forçar o administrador a realizar a segunda fase, sob a ameaça de que, caso não cumpra, o acordo será revelado. ${ }^{11}$ Ou seja, existência de programas de leniência é capaz de, paradoxalmente, gerar a estabilização de acordos ilícitos, uma vez que a possibilidade de uma das partes denunciarem para obter redução nas sanções pode ser utilizada como uma ameaça crível para garantir o cumprimento de acordos que, de outro modo, não seriam cumpridos por se tratarem de acordos do tipo one-shot. Com isso, cria-se a oportunidade de as partes engajadas em acordos corruptos punirem padrões desviantes da prática corrupta, gerando a estabilização dos acordos ilícitos. ${ }^{92}$

Para enfrentar essa externalidade negativa de estabilização de acordos, há no mínimo três opções estudadas pela literatura internacional: (i) o programa de leniência não pode reduzir as sanções para as partes abaixo da sanção total esperada; (ii) oferecer recompensas para ao menos um dos agentes envolvidos acima do ganho esperado com a transação ilegal; (iii) a chamada leniência assimétrica.

A primeira alternativa - não poder reduzir as sanções para as partes abaixo da sanção total esperada - faz com que nem o agente privado nem o agente público possam fazer ameaças críveis de denunciar a transação ilegal caso a outra parte não cumpra o acordo. Nesta hipótese, realizar o acordo não reduziria suas penalidades para valores abaixo do que obteriam em caso de não haver o acordo, o que torna a celebração de acordos uma ameaça não crível. Contudo, essa tentativa de evitar a externalidade negativa acaba com a própria possibilidade de se firmar acordos de leniência, uma vez que o agente não teria incentivos para denunciar atos ilícitos cometidos por outros se ele não obtivesse redução de penalidade. A consequência dessa condição é a redução da atratividade da leniência para agentes envolvidos em relações ilícitas de longo prazo. ${ }^{93}$

A segunda faz com que não apenas haja uma diminuição na externalidade negativa apresentada como também aumente a atratividade do acordo de leniência. ${ }^{94}$ Spagnolo argumenta que o modelo ideal é aquele

\footnotetext{
90 SPAGNOLO, Giancarlo. Leniency and whistleblowers in antitrust. In: BUCCIROSSI, Paolo (org.). Handbook of Antitrust Economics. Cambridge: MIT Press, 2006. p. 262. Umas das possibilidades é o oferecimento de bônus, sendo normalmente o modelo idealmente mais eficaz no combate à corrupção. Esse modelo é analisado por AUBERT, Cécile; REY, Patrick; KOVACIC, William. The impact of leniency programs on cartels. University of Toulouse, 2003; APESTEGUIA, Jose; DUFWENBERG, Martin; SELTEN, Reinhard. Blowing the whistle. Economic Theory, v. 31, n. 1, p. 143-166, 2007; SPAGNOLO, Giancarlo. Optimal leniency programs. FEEM Working Paper n. 42, 2000.

91 BUCCIROSSI, Paolo; SPAGNOLO, Giancarlo. Leniency policies and illegal transactions. Journal of Public Economics, v. 90, n. 6, p. 12811297, 2006. p. 1283. Apesar de esta ser uma possibilidade plausível levantada por uma série de autores, Jan Schikora critica esses resultados por desconsiderarem as duas externalidades negativas da corrupção: (i) direta, com a apropriação de recursos e (ii) indireta, com algumas entidades privadas deixando de entrar em determinados mercados nos quais há a possibilidade de serem solicitados subornos por agentes públicos (SCHIKORA, Jan Theodor. Bringing good and bad whistle-blowers to the lab. University of Munich: Munich discussion paper, 2011).

92 SPAGNOLO, Giancarlo. Leniency and whistleblowers in antitrust. In: BUCCIROSSI, Paolo (org.). Handbook of Antitrust Economics. Cambridge: MIT Press, 2006. p. 275.

93 BUCCIROSSI, Paolo; SPAGNOLO, Giancarlo. Leniency policies and illegal transactions. Journal of Public Economics, v. 90, n. 6, p. 1281-1297, 2006. p. 1292.

94 BUCCIROSSI, Paolo; SPAGNOLO, Giancarlo. Leniency policies and illegal transactions. Journal of Public Economics, v. 90, n. 6, p. 1281-1297, 2006, p. 1292.
} 
segundo o qual o regulador oferece ao denunciante a soma de todas as penalidades aplicadas àqueles que foram condenados em decorrência de sua denúncia. ${ }^{95} \mathrm{Com}$ isso, o Estado não precisaria investir na busca de informações porque os participantes de atos ilícitos teriam incentivos desalinhados, de modo que invariavelmente alguém denunciaria.

No entanto, esse modelo não é ética e socialmente aceito pela sociedade por envolver remuneração de agentes que cometem atos ilícitos. Apesar disso, há experiências bem-sucedidas de seu funcionamento. Para casos concorrenciais, o programa de Leniência Plus (Amnesty Plus) nos Estados Unidos é considerado um exemplo de sucesso pelo Departamento de Justiça norte americano, juntamente ao US False Claim Act, que permite a indivíduos denunciarem empresas que tenham cometido fraudes contra o governo federal. No caso da Coreia, por exemplo, há um programa de remuneração para denunciantes, mas a remuneração dada é ainda muito baixa de modo a compensar as consequências reputacionais de delatar. ${ }^{96}$

Caso o oferecimento de remuneração não seja aceito socialmente, o segundo melhor modelo leva em consideração restrições sobre as penas ou recompensas. Em ambos os casos, a regulação ótima envolve juntar recompensas com investigação ativa. ${ }^{97}$ Ou seja, sua eficácia depende das capacidades de investigação presentes em cada contexto, atuando como mecanismo complementar.

A terceira possível opção é a leniência assimétrica (asymmetric leniency), que diferencia as recompensas dadas a cada um dos atores de modo que não possa ser usado como um seguro garantidor de retribuição do agente público. ${ }^{98}$ No modelo específico descrito por Schikora, as sanções devem ser altas por oferecer subornos e por realizar a contraprestação (i.e., modificar os resultados de uma licitação) e relativamente baixas pelos atos de aceitar o suborno e aceitar o tratamento favorável..$^{99}$

Com a introdução da assimetria de penas, o efeito de estabilização da corrupção é, ao menos parcialmente, mitigado porque oferece ao oficial a oportunidade de descumprir o acordo (segunda fase) e, ao mesmo tempo, se beneficiar do suborno e se proteger contra possíveis retaliações do cliente. ${ }^{100}$ Dito de outra forma, com o modelo de leniência assimétrica, é possível que o funcionário público não realize a contraprestação no acordo sem incorrer no risco de ser penalizado pelo cliente por meio da denúncia.

Apesar da proposta de solução para a externalidade negativa de estabilização de acordos ilícitos, outro problema enfrentado quando estamos lidando com incentivos é o fato de os resultados dependerem das especificidades de determinados setores e de determinados agentes. Por exemplo, Hamaguch, Kawagoe e Shibata argumentam que uma série de fatores influenciam a eficácia dos programas de leniência para cartéis, dentre eles a quantidade de participantes do conluio e o grau de recompensas aos denunciantes. ${ }^{101}$

\section{Instituições}

\footnotetext{
95 SPAGNOLO, Giancarlo. Divide et impera: Optimal leniency programs CEPR Discussion paper n. 4840, 2004.

96 SPAGNOLO, Giancarlo. Leniency and whistleblowers in antitrust. In: BUCCIROSSI, Paolo (org.). Handbook of Antitrust Economics. Cambridge: MIT Press, 2006. p. 290-292.

97 SPAGNOLO, Giancarlo. Divide et impera: Optimal leniency programs CEPR Discussion paper, n. 4840, p. $20,2004$.

98 SCHIKORA, Jan Theodor. Bringing good and bad whistle-blowers to the lab; LAMBSDORFF, Johann; NELL, Mathias, Fighting corruption with asymmetric penalties and leniency, CEGE Discussion Papers, 2007; BUCCIROSSI; BUCCIROSSI, Paolo; SPAGNOLO, Giancarlo. Leniency policies and illegal transactions. Journal of Public Economics, v. 90, n. 6, p. 1281-1297, 2006; LAMBSDORFF, Johann. The Organization of Anticorruption: Getting Incentives Right. In: CORRUPTION, global security, and world order. Baltimore: Brookings Institution Press, 2009, p. 389-415.

99 SCHIKORA, Jan Theodor. Bringing good and bad whistle-blowers to the lab. University of Munich: Munich discussion paper, 2011. p. 4.

100 SCHIKORA, Jan Theodor. Bringing good and bad whistle-blowers to the lab. University of Munich: Munich discussion paper, 2011. p. 30 .

101 HAMAGUCHI, Yasuyo; KAWAGOE, Toshiji; SHIBATA, Aiko. Group size effects on cartel formation and the enforcement power of leniency programs. International Journal of Industrial Organization, v. 27, n. 2, p. 145-165, 2009.
} 
Outra estratégia regulatória disponível é aquela voltada ao desenho de instituições, seja para a criação de novas entidades, modificações de competências, ou estabelecimento de relações entre agências já existentes. Ao contrário do que ocorre com as estratégias regulatórias baseadas em incentivos, o regulador deve estabelecer o funcionamento de instituições que sejam eficazes independentemente dos agentes que ocuparão seus cargos.

Imaginemos um regulador que esteja preocupado com subornos no poder judiciário. Pensando em termos de instituições, poderia confiar que o sistema de recursos para órgãos colegiados é capaz de diminuir possíveis subornos em primeira instância. Ou seja, mesmo que um juiz de primeiro grau seja corrompido, haverá a possibilidade de novo julgamento por um colegiado, cuja possibilidade de suborno é possivelmente menor. Nesse caso, não se está pensando em quem toma as decisões, mas sim em um ambiente no qual as decisões são tomadas, modificando aspectos para que haja diminuição de corrupção.

Naturalmente, as instituições sozinhas não são capazes de eliminar a corrupção. No entanto, aliadas a outras estratégias, podem gerar efeitos bastante importantes no combate à corrupção.

\subsection{Anti-corruption Agencies (ACAs)}

A estratégia baseada em instituições mais evidente para o combate à corrupção é a criação de uma agência voltada especificamente para este fim. Apesar de parecer uma resposta quase intuitiva, pequenas variações em seu desenho podem afetar, drasticamente, sua efetividade.

O Judiciário é normalmente um dos atores principais no julgamento de casos de corrupção, de modo que sua independência - interna e externa - parece ser condição necessária para evitar ingerências indevidas sobre o processo. No entanto, Ríos-Figueroa argumenta que um nível intermediário de independência judicial seria ótimo para o controle de corrupção, já que evitaria controladores não controlados (unchecked chekers) e minimizaria os incentivos para funcionários públicos usarem dinheiro público para ganhos particulares. ${ }^{102} \mathrm{O}$ nível de corrupção dentro do Judiciário é diretamente proporcional à independência interna, isto é, "mais independência interna está positivamente relacionada à corrupção, porque muitos tribunais inferiores descentralizados, mal monitorados e irrestritos podem aumentar os incentivos para os juízes inferiores aceitarem subornos".

Assim como a independência do Judiciário pode não ter os efeitos intuitivamente esperados, o desenho de uma instituição de combate à corrupção também enfrenta uma série de questionamentos. Quais são os requisitos mínimos para que consigam funcionar? A qual dos poderes deve estar ligada? Quais são os atores que devem integrar este órgão e quais suas funções? Como deve ocorrer o processo de nomeação do agente designado para o monitoramento? Algumas experiências podem ajudar a pensar em um modelo adequado para a realidade brasileira.

O caso de Hong Kong é considerado de sucesso, tendo reduzido, drasticamente, os níveis de corrupção. O mais importante fator foi a criação de uma statutory agency chamada "Comissão Independente Contra a Corrupção" (Independent Comission Against Corruption - ICAC). Seu desenho envolveu quatro características essenciais. ${ }^{103}$ Logo em sua criação, foi garantida independência à agência, sendo obrigada a reportar-se apenas ao chefe do executivo, evitando interferência indevidas. Em segundo lugar, estabeleceu uma estratégia de longo prazo composta por três pontos: (i) um sistema legal abrangente e efetivo, (ii) aplicação da lei, combinado com prevenção e educação e (iii) criação de mecanismo de freios e contrapesos para evitar abusos de poder. Terceiro, alocação de fundos e pessoas qualificadas, tendo uma das maiores destinações de recursos para o combate à corrupção (\$15 per capta). Quarto, a criação de programas para proativamente comunicar à população uma cultura de

102 RIOS-FÍGUEROA, Julio. Justice system institutions and corruption control: evidence from Latin America. Justice System Journal, v. 33, n. 2, p. 195-214, 2012. p. 200.

103 HUI, Wingchi. Combating Corruption: The Hong Kong Experience (October 31, 2013). Tsinghua China Law Review, v. 6, p. 250-256, 2013. 
probidade e de integridade, garantindo a cooperação e confiança da população no combate à corrupção.

A experiência de Hong Kong, por se basear em estratégias de longo prazo e de mudança estrutural, gerou um enorme custo tanto monetário quanto político para que fosse bem-sucedida. ${ }^{104}$ Uma série de países tentaram implementar esse modelo de agências, mas sem sucesso. Normalmente, os obstáculos em países em desenvolvimento são, segundo Johnsøn, Taxel e Zaum: ${ }^{105}$ falta de independência contra possíveis capturas políticas, ${ }^{106}$ falta de vontade política, ausência de suporte financeiro ${ }^{107}$ e mandatos fracos (weak mandates). ${ }^{108}$

A Comissão Independente da Agência Contra a Corrupção (Independent Anti-Corruption Agency Comission) em Bangladesh, teoricamente, era uma agência com amplos poderes, incluindo o direito de investigar qualquer agente público que sofresse alegações de praticar atos de corrupção. Na prática, por outro lado, teve seu trabalho seriamente comprometido, já que a legislação não permitia o acesso a registros bancários e financeiros nem seu acesso a transações internacionais, impedindo a investigação de empresas multinacionais. Isso além de seu orçamento e administração serem controlados pelo governo nacional, o que foi agravado ao longo do tempo com a necessidade de autorização do Executivo para que a agência tomasse medidas contra funcionários públicos. ${ }^{109}$ Os mesmos problemas foram encontrados pelas agências criadas no Quênia ${ }^{110}$ e Coreia do Sul. ${ }^{111}$ Já a agência polonesa criada em 2006, apesar de ter amplos poderes de investigação, prevenção e disseminação de informações, foi acusada de ser uma ferramenta política do governo para gerar descrédito sobre oponentes ${ }^{112}$. Dessa forma, o entusiasmo seguinte à criação das ACAs nesses países não gerou efetivas mudanças na realidade, já que os problemas no desenho institucional - decorrentes da falta de vontade política - retiraram a efetividade das agências.

Uma das possíveis formas de combater esses problemas é por meio do aprimoramento dos órgãos de fiscalização. Alt e Lassen testam a hipótese, defendida por Montesquieu, de que o Judiciário serve como mecanismo de fiscalização do Legislativo e Executivo quando os dois atuam unificadamente (i.e., quando são eleitos pelos mesmos meios ou têm interesses alinhados). ${ }^{113}$ Os autores verificaram que, nesses casos de unicidade, a presença de uma Suprema Corte estadual composta por juízes eleitos - em contraste com juízes nomeados - está associada a menores níveis de corrupção. Os mesmos resultados são encontrados por Azfar e Nelson, ao conduzirem um experimento em laboratório. ${ }^{114}$ Os procuradores gerais eleitos diretamente são mais vigilantes no controle de corrupção do que aqueles nomeados.

Ainda, aprimorando aspectos do quadro de funcionários públicos, Rauch e Evans argumentam que o elemento mais importante para a melhora das estruturas burocráticas é a utilização de recrutamento meritocrático. ${ }^{115}$ A diminuição do nepotismo tende a reduzir a probabilidade com a qual o controle interno

104 DOIG, Alan; RILEY, Stephen. Corruption and anti-corruption strategies: Issues and case studies from developing countries. Corruption and integrity improvement initiatives in developing countries, v. 45, p. 62, 1998. p. 58.

105 JOHNSØN, Jesper; TAXELL, Nils; ZAUM, Dominik. Mapping evidence gaps in anti-corruption: Assessing the state of the operationally relevant evidence on donors' actions and approaches to reducing corruption. U4 Issue, v. 2012, n. 7, 2012 . p. 11.

106 HUSSMANN, Karen; HECHLER, Hannes; PEÑAILILLO, Miguel. Institutional arrangements for corruption prevention: Considerations for the implementation of the United Nations Convention against Corruption Article 6, U4 Issue, v. 2009 , n. 4 , 2009.

107 TANGRI, Roger; MWENDA, Andrew M. Politics, donors and the ineffectiveness of anti-corruption institutions in Uganda. The Journal of Modern African Studies, v. 44, n. 1, p. 101-124, 2006; DOIG, Alan; WATT, David; WILLIAMS, Robert. Why do developing country anti-corruption commissions fail to deal with corruption? Understanding the three dilemmas of organisational development, performance expectation, and donor and government cycles, Public Administration and Development, v. 27, n. 3, p. $251-259,2007$. 108 HUSSMANN, Karen; HECHLER, Hannes; PEÑAILILLO, Miguel. Institutional arrangements for corruption prevention: Considerations for the implementation of the United Nations Convention against Corruption Article 6. U4 Issue, v. 2009 , n. 4, 2009.

109 HOUGH, Dan. Corruption, anti-corruption and governance. UK: Palgrave Macmillan, 2013. cap. 3.

110 HOUGH, Dan. Corruption, anti-corruption and governance. UK: Palgrave Macmillan, 2013. cap. 3.

111 HOUGH, Dan. Corruption, anti-corruption and governance. UK: Palgrave Macmillan, 2013. cap. 4

112 HOUGH, Dan. Corruption, anti-corruption and governance. UK: Palgrave Macmillan, 2013. p. 89.

113 ALT, James E; LASSEN, David D. Political and judicial checks on corruption: Evidence from American state governments. Economics \& Politics, v. 20, n. 1, p. 33-61, 2008.

114 AZFAR, Omar; NELSON, William Robert. Transparency, wages, and the separation of powers: An experimental analysis of corruption. Public Choice, v. 130, n. 3, p. 471-493, 2007.

115 RAUCH, James E; EVANS, Peter B. Bureaucratic structure and bureaucratic performance in less developed countries. Journal of public economics, v. 75, n. 1, p. 49-71, 2000. 
seria eliminado pela presença de colusão entre os agentes públicos. Assim, tanto os mecanismos de eleição quanto os meritocráticos parecem ser capazes de melhorar a performance das instituições.

Na Alemanha, por outro lado, a solução não caminhou no sentido de criar uma agência anticorrupção especializada. Desenvolveram uma cultura segundo a qual a prevenção é responsabilidade de vários órgãos de supervisão ao passo que a repressão é realizada por agência responsável pela aplicação da lei. ${ }^{116}$

\subsection{Sobreposição ou Multiplicidade Institucional}

Além de criar instituições ou aparelhá-las para o combate à corrupção, como visto acima, é possível pensar no tipo de relacionamento que uma instituição terá com as outras. Criar uma multiplicidade institucional faz com que mais de uma instituição seja encarregada de determinadas funções.

Como visto no tópico acima, um dos grandes obstáculos da criação de agência anticorrupção é a falta de vontade política, que acabou gerando o fracasso em diversas tentativas ao redor do mundo. A multiplicidade institucional não sofre este problema porque adiciona uma nova instituição sem modificar o modo de operação das já existentes, sendo menos suscetível a pressões políticas. ${ }^{117}$ Essa multiplicidade pode ser abordada de duas maneiras diferentes: redução das oportunidades de corrupção (mecanismo ex ante) e mecanismos expost. ${ }^{118}$

A criação de competição entre agências é uma forma de evitar que indivíduos sejam obrigados a oferecer subornos a agentes públicos. Se uma empresa é qualificada para receber um benefício do governo apenas por meio de um determinado funcionário público ou agência, poderá ser obrigada a pagar suborno para conseguir o que já tem direito. Em um cenário de competição entre agências, o poder de barganha dos indivíduos é aumentado, de modo que pode simplesmente buscar outra agência caso a primeira solicite pagamentos indevidos ${ }^{119} \mathrm{e}$, consequentemente, diminuindo os níveis de corrupção. ${ }^{120}$

No entanto, não há na literatura um argumento empírico convincente que relacione o estabelecimento de mecanismos de competição ex ante com reduções nos níveis de corrupção. ${ }^{121}$ Há uma série de consequências negativas que podem advir do estabelecimento de competição. Shleifer e Vishny demonstram, por exemplo, que, mesmo havendo uma diminuição dos subornos, a quantidade de dinheiro desviado do governo pode aumentar. ${ }^{122}$ Já Rose-Ackerman e Truex ${ }^{123}$ mostram uma incompatibilidade entre a utilização de rotação de funcionários e o estabelecimento de competição a partir do estudo de Sequeira e Djankov. ${ }^{124}$ Com a presença das duas estratégias anticorrupção concomitantemente, os oficiais dispõem de um curto período de tempo para obter retornos ilícitos, por mais que isso gere um desvio da demanda para outra agência - no caso do estudo, outro porto - em longo prazo.

Além disso, suponhamos que os agentes públicos de uma determinada agência não estejam prestando os serviços de maneira adequada. Os agentes privados irão buscarão uma solução em outra agência, em vez de reclamar com os superiores daquele funcionário público. ${ }^{125}$ Suponhamos o cenário apresentado por

116 HOUGH, Dan. Corruption, anti-corruption and governance. UK: Palgrave Macmillan, 2013. p. 100-105.

117 PRADO, Mariana Mota; CARSON, Lindsey. Brazilian anti-corruption legislation and its enforcement: potential lessons for institutional design. RIBA Working Paper n. 09, p. 8-9, 2014.

118 PRADO, Mariana Mota; CARSON, Lindsey. Brazilian anti-corruption legislation and its enforcement: potential lessons for institutional design. RIBA Working Paper n. 09, p. 8, 2014.

119 ROSE-ACKERMAN, Susan; TRUEX, Rory. Corruption and policy reform. 2012. p. 20.

120 ROSE-ACKERMAN; PALIFKA. Corruption and government: Causes, consequences, and reform; ROSE-ACKERMAN, Susan.

The law and economics of bribery and extortion. Annual Review of Law and Social Science, v. 6, p. 217-238, 2010.

121 SVENSSON, Jakob. Eight questions about corruption. The Journal of Economic Perspectives, v. 19, n. 3, p. 19-42, 2005. p. 34.

122 SHLEIFER, Andrei; VISHNY, Robert W. Corruption. The quarterly journal of economics, v. 108, n. 3, p. 599-617, 1993.

123 ROSE-ACKERMAN; TRUEX. Corruption and policy reform. p. 20.

124 SEQUEIRA, Sandra; DJANKOV, Simeon. An empirical study of corruption in ports. 2010.

125 BARDHAN, Pranab. Corruption and development: a review of issues. Journal of economic literature, v. 35, n. 3, p. 1320-1346, 1997. p. 1337. 
Svensson, ${ }^{126}$ no qual pais de alunos da Uganda, diante do desvio de verbas de uma escola têm duas opções: exercer saída ou voz. Com a presença de competição, em vez de realizar reclamações formais ou informais, simplesmente irá mudar o filho de escola. Consequentemente, os oficiais corruptos locais poderão extrair um número ainda maior de dinheiro desviado da escola. ${ }^{127}$

Já a utilização de mecanismos ex post parece ser uma proposta promissora para a solução de alguns dos problemas enfrentados pelo Brasil nas etapas de monitoramento, investigação e punição de atos de corrupção. Lindsey Carson e Mariana Prado demonstram, em estudo realizado em 2016, ${ }^{128}$ que o problema da corrupção brasileira está nas instituições brasileiras que permitem a existência de grandes níveis de corrupção. E, em outro artigo publicado no mesmo ano, ${ }^{129}$ as autoras mostram que a existência de sobreposição entre as funções das agências é capaz de gerar três possíveis interações. Primeiro, se uma instituição falhar em cumprir seus objetivos, outra está igualmente equipada para cumpri-lo, em um mecanismo de compensação. A segunda vantagem é que há uma colaboração, havendo aumento da quantidade de pessoas e de recursos envolvidos para realizar a mesma tarefa. Por fim, é possível vislumbrar um efeito de complementariedade, que pode ser benéfico dada a especialidade de diversas agências que se completam. ${ }^{130}$

Para ilustrar o funcionamento da sobreposição institucional, as autoras analisam, dentre outras, as duas instituições responsáveis pelo monitoramento das instituições brasileiras, a Controladoria Geral da União (CGU) e o Tribunal de Contas da União (TCU). O TCU tinha uma série de problemas que diminuíam sua efetividade no combate à corrupção, mas a existência da multiplicidade institucional foi capaz de superar estes problemas em alguma medida. O esquema de desvio de dinheiro para a compra de ambulâncias não foi descoberto pelos procedimentos ossificados do Tribunal de Contas, sendo apenas descoberto pelas auditorias sobre licitações realizadas pela CGU, dando origem à Operação Sanguessuga. ${ }^{131}$

Esse caso pode ser interpretado de duas formas diferentes, de acordo com as autoras. Caso se entenda que o procedimento adotado pela CGU é mais eficiente no combate à corrupção, ou seja, que há uma falha no procedimento de auditoria do TCU, há uma compensação entre as duas agências. Por outro lado, o resultado pode ser, apenas, em decorrência da complementariedade por utilizarem procedimentos de diferentes auditorias. Independentemente da interpretação, o fato é que "em uma tentativa de analisar a efetividade do programa federal no nível local, a CGU descobriu uma série de irregularidades no uso de fundos federais". ${ }^{132}$

No entanto, o nível de sobreposição de instituições no estágio de punição é consideravelmente mais baixo se comparado ao monitoramento e investigação. O Judiciário brasileiro tem monopólio sobre o poder de punição por ser a última instância na qual todas as sanções de outras agências podem ser revistas. Essa ausência de multiplicidade pode reduzir as chances de punição, já que possíveis falhas do Judiciário não serão consertadas por outras agências. ${ }^{133}$ Uma das propostas para resolver esse problema é a criação de uma "justiça anticorrupção", de modo a gerar uma sobreposição também no nível de punição. ${ }^{134}$

126 SVENSSON, Jakob. Eight questions about corruption. The Journal of Economic Perspectives, v. 19, n. 3, p. 19-42, 2005.

127 SVENSSON, Jakob. Eight questions about corruption. The Journal of Economic Perspectives, v. 19, n. 3, p. 19-42, 2005. p. 34.

128 CARSON, Lindsey D; PRADO, Mariana Mota. Using institutional multiplicity to address corruption as a collective action problem: Lessons from the Brazilian case. The Quarterly Review of Economics and Finance, v. 62, p. 56-65, 2016.

129 PRADO, Mariana Mota; CARSON, Lindsey. Brazilian anti-corruption legislation and its enforcement: potential lessons for institutional design. RIBA Working Paper n. 09, 2014.

130 PRADO, Mariana Mota; CARSON, Lindsey. Brazilian anti-corruption legislation and its enforcement: potential lessons for institutional design. RIBA Working Paper, n. 09, p. 9, 2014.

131 PRADO, Mariana Mota; CARSON, Lindsey. Brazilian anti-corruption legislation and its enforcement: potential lessons for institutional design. RIBA Working Paper, n. 09, p. 11, 2014.

132 Tradução livre. No original: "in an attempt to analyze the effectiveness of a federal program at the local level, the CGU has uncovered a series of irregularities in the use of federal funds". PRADO, Mariana Mota; CARSON, Lindsey. Brazilian anti-corruption legislation and its enforcement: potential lessons for institutional design. RIBA Working Pape, r n. 09, p. 11, 2014.

133 PRADO, Mariana Mota; CARSON, Lindsey. Brazilian anti-corruption legislation and its enforcement: potential lessons for institutional design. RIBA Working Paper, n. 09, p. 17-18, 2014; CARSON, Lindsey; PRADO, Mariana Mota. Mapping Corruption \& its Institutional Determinants in Brazil. IRIBA Working Paper, n. 08, 2014.

134 Punição a corruptos tem apenas valor simbólico, diæpesquisadora - 16/12/2013 - Poder, Folha de S.Paulo, disponível em: http://www1. 
A sobreposição de instituições é estudada pela literatura sobre estratégias regulatórias há muitos anos, de modo que alguns custos e benefícios de tal estratégia já foram identificados. Uma série de potenciais benefícios podem ser alcançados com a sobreposição institucional. Para facilitar a análise dos benefícios, pode-se separar a atuação de agências em dois estágios: (i) busca e análise de informações e (ii) decisão e execução.

No que se refere à busca e análise de informações, quatro são os potenciais benefícios apresentados pela literatura. Primeiro, cada agência tenderá a buscar informação e desenvolver argumentos que justifiquem sua decisão - dado que poderá, eventualmente, ser confrontada por decisão oposta de outra agência analisando o mesmo tema -, o que tenderá a aumentar a qualidade e a quantidade das evidências apresentadas. Segundo, caso haja uma discordância de outra agência, ela buscará avaliar as informações produzidas pela outra instituição, o que, em longo prazo, cria um mecanismo de revisões recíprocas do processo decisório de ambas as agências. Terceiro, é possível que agências diferentes olhando para os mesmos problemas possam gerar novas informações, argumentos e soluções que de outro modo não seriam gerados, uma vez que cada instituição se difere por sua história, tradição, método de trabalho, personalidade dos integrantes, liderança etc. que dificilmente são duplicáveis. Por fim, com a multiplicidade de pontos de vista, cada agência será obrigada a levar em consideração os diversos objetivos e interesses de cada medida, o que melhorará a qualidade dos argumentos apresentados, dos questionamentos a eventuais contra-argumentos e da própria consideração de posições contrárias. ${ }^{135}$

Já em relação às fases de decisão e execução de uma agência, a multiplicidade institucional também pode gerar benefícios. Primeiro, caso uma das instituições não realize determinada tarefa, ainda assim é possível que outra realize. Isto é ainda mais provável em um contexto em que as próprias agências atuam em competição. Segundo, caso uma agência falhe em parte ou na totalidade na realização de suas atribuições, estas eventuais falhas podem ser corrigidas ou compensadas pela atuação da outra. Terceiro, como há mais de um ator voltado para a realização de uma mesma tarefa, passa-se a mensagem para a população de que o governo de fato se preocupa com aquela atividade. Por fim, com a multiplicidade, várias formas diferentes de abordar os problemas são adotadas, gerando uma miríade de respostas flexíveis para os problemas que venham a surgir. ${ }^{136}$

Contudo, a criação de múltiplas instituições pode gerar alguns custos desnecessários e efeitos negativos sobre a qualidade das decisões. Isto é, pode ser que diferentes agências com diferentes atribuições estejam realizando, de modo independente, a coleta de informações e a sua análise, de modo que haveria uma duplicação de custos e não seria possível alcançar economias de escala. ${ }^{137}$ Além disso, dois outros problemas podem surgir. Em primeiro lugar, é possível que a competição entre as agências faça com que uma delas busque retomar a autonomia e evitar a autoridade compartilhada sobre determinado problema, passando a esconder ou distorcer informações que sejam contrárias à sua posição para evitar contra-argumentos da agência concorrente. Em segundo lugar, caso um dos atores tenha poder de veto, eventualmente tal poder pode ser utilizado para bloquear ações que atendam aos interesses sociais. ${ }^{138}$

\section{Considerações finais}

folha.uol.com.br/poder/2013/12/1386052-punicao-a-corruptos-tem-apenas-valor-simbolico-diz-pesquisadora.shtml. Acesso em: 1 set. 2017.

135 SIRICO JR, Louis J. Agencies in Conflict: Overlapping Agencies and the Legitimacy of the Administrative Process. Vand. L. Rev., v. 33, p. 101, 1980. p. 126-127.

136 SIRICO JR, Louis J. Agencies in Conflict: Overlapping Agencies and the Legitimacy of the Administrative Process. Vand. L. Rev., v. 33, p. 101, 1980. p. 127-128.

137 SIRICO JR, Louis J. Agencies in Conflict: Overlapping Agencies and the Legitimacy of the Administrative Process. Vand. L. Rev., v. 33, p. 101, 1980. p. 125-126.

138 SIRICO JR, Louis J. Agencies in Conflict: Overlapping Agencies and the Legitimacy of the Administrative Process. Vand. L. Rev., v. 33, p. 101, 1980. p. 128-131. 
A análise de métodos de combate à corrupção realizada à luz das estratégias regulatórias nos permitiu classificar os métodos anticorrupção em quatro grupos: comando e controle, transparência, incentivos e instituições. A revisão de literatura e de leis sobre corrupção no mundo já foi realizada por diversos autores, mas percebemos que há uma lacuna de uma análise sistemática e abrangente sobre a literatura que possa trazer ideias que eventualmente sejam aplicadas - e que já vêm sendo aplicadas - no Brasil.

Todas as estratégias que analisamos apresentam prós e contras, de modo que a conclusão mais importante que se pode tirar de um estudo como o realizado é de que o investimento em uma só estratégia não solucionará problemas de anticorrupção. Por exemplo, estratégias baseadas em comando e controle são necessariamente dependentes de mecanismos de transparência - que ajudam em sua aplicação - que, por sua vez, podem ser muito custosos e até danosos a depender do tipo de informação divulgada. Ao que nos parece, hoje há uma tendência maior de investimento em comando e controle, como é possível ver no caso das Novas Medidas Contra a Corrupção, o que não é necessariamente uma estratégia adequada para a solução das causas da corrupção.

Também foi possível perceber, ao longo do presente artigo, que as estratégias apresentadas podem ser visualizadas como um crescente de sofisticação e de custos para lidar com os problemas. Normalmente, estratégias de comando e controle são relativamente mais simples de serem implementadas, ao passo que a criação de instituições ou até mesmo o estabelecimento de sua coordenação regulatória pode ser um mecanismo mais custoso, porém muitas vezes, mais efetivo.

\section{Referências}

ABBINK, Klaus. Fair salaries and the moral costs of corruption. Bonn Econ Discussion Papers, 2000.

ABBINK, Klaus; SERRA, Danila. Chapter 4 Anticorruption Policies: Lessons from the Lab. In: SERRA, Danila; WANTCHEKON, Leonard (org.). New advances in experimental research on corruption. UK: Emerald Group Publishing Limited, 2012. p. 77-115.

ABLO, Emmanuel; REINIKKA, Ritva. Do budgets really matter? Evidence from public spending on education and health in Uganda. 1998.

ABRAMO, Claudio Weber. Acesso a informação e eficiência do Estado. Revista gov. sp, n 2, 2004.

AKERLOF, George A; YELLEN, Janet L. The fair wage-effort hypothesis and unemployment. The Quarterly Journal of Economics, v. 105, n. 2, p. 255-283, 1990.

ALT, James E; LASSEN, David D. Political and judicial checks on corruption: Evidence from American state governments. Economics \& Politics, v. 20, n. 1, p. 33-61, 2008.

ANDERSEN, Thomas Barnebeck. E-Government as an anti-corruption strategy. Information Economics and Policy, v. 21, n. 3, p. 201-210, 2009.

APESTEGUIA, Jose; DUFWENBERG, Martin; SELTEN, Reinhard. Blowing the whistle. Economic Theory, v. 31, n. 1, p. 143-166, 2007.

ARMANTIER, Olivier; BOLY, Amadou. Can corruption be studied in the lab? Comparing a field and a lab experiment. 2008.

AUBERT, Cécile; REY, Patrick; KOVACIC, William. The impact of leniency programs on cartels. University of Toulouse, 2003.

AVIS, Eric; FERRAZ, Claudio; FINAN, Frederico, Do Government Audits Reduce Corruption?. Journal of Political Economy, v. 126, n. 5, p. 1912-1964, 2018. 
AZFAR, Omar; NELSON, William Robert. Transparency, wages, and the separation of powers: An experimental analysis of corruption. Public Choice, v. 130, n. 3, p. 471-493, 2007.

BAC, Mehmet. Corruption, connections and transparency: Does a better screen imply a better scene? Public Choice, v. 107, n. 1-2, p. 87-96, 2001.

BALDWIN, Robert; CAVE, Martin; LODGE, Martin. Understanding regulation: theory, strategy, and practice. New York: Oxford University Press, 2012.

BANERJEE, Abhijit et al. Do informed voters make better choices? Experimental evidence from urban India. Unpublished manuscript, 2011.

BARDHAN, Pranab. Corruption and development: a review of issues. Journal of economic literature, v. 35, n. 3 , p. 1320-1346, 1997.

BARR, Abigail; LINDELOW, Magnus; SERNEELS, Pieter M. To serve the community or oneself: the public servant's dilemma. World Bank Policy Research working paper n. WPS 3187, 2004.

BECKER, Gary S; STIGLER, George J. Law enforcement, malfeasance, and compensation of enforcers. The Journal of Legal Studies, v. 3, n. 1, p. 1-18, 1974.

BESLEY, Timothy; MCLAREN, John. Taxes and bribery: the role of wage incentives. The economic journal, v. 103, n. 416, p. 119-141, 1993.

BESLEY, Timothy; PRAT, Andrea. Handcuffs for the grabbing hand? Media capture and government accountability. The American Economic Review, v. 96, n. 3, p. 720-736, 2006.

BLACK, Julia. Decentring regulation: Understanding the role of regulation and self-regulation in a "post-regulatory" world. Current legal problems, v. 54, n. 1, p. 103-146, 2001.

BOBONIS, Gustavo J; FUERTES, Luis Cámara R; SCHWABE, Rainer. Monitoring Corruptible Politicians. The American Economic Review, v. 106, n. 8, p. 2371-2405, 2016.

BRASIL. Ministério Público Federal. As 10 Medidas Contra a Corrup̣ão: Propostas do Ministério Público Federal para o combate à corrupção e à impunidade. Disponível em: http://www.dezmedidas.mpf.mp.br/ campanha/documentos/resumo-medidas.pdf. Acesso em: 14 jun. 2019.

BRASIL. Projeto de Lei 4.850/2016. Disponível em: https://www.camara.leg.br/proposicoesWeb/fichadetr amitacao?idProposicao $=2080604$.

BROOKS, Graham et al. Defining Corruption. In: BROOKS, Graham; WALSH, David; LEWIS, Chris; et al (org.). Preventing Corruption: Investigation, Enforcement and Governance. London: Palgrave Macmillan UK, 2013. p. 11-26. Disponível em: https://doi.org/10.1057/9781137023865_2.

BRUNETTI, Aymo; WEDER, Beatrice. A free press is bad news for corruption. Journal of Public Economics, v. 87, n. 7, p. 1801-1824, 2003.

BUCCIROSSI, Paolo; SPAGNOLO, Giancarlo. Leniency policies and illegal transactions. Journal of Public Economics, v. 90, n. 6, p. 1281-1297, 2006.

CALLAND, Richard. Access to Information: How Is It Useful and How Is It Used? NEUMAN, Laura. Access to information: a key to democracy. Atlanta: The Carter Center, 2002.

CARLO BERTOT, John; JAEGER, Paul T; GRIMES, Justin M. Promoting transparency and accountability through ICTs, social media, and collaborative e-government. Transforming Government: People, Process and Policy, v. 6, n. 1, p. 78-91, 2012.

CARSON, Lindsey; PRADO, Mariana Mota. Mapping Corruption \& its Institutional Determinants in Brazil. IRIBA Working Paper n. 08, 2014. 
CARSON, Lindsey D; PRADO, Mariana Mota. Using institutional multiplicity to address corruption as a collective action problem: Lessons from the Brazilian case. The Quarterly Review of Economics and Finance, v. 62, p. 56-65, 2016.

CHOWDHURY, Shyamal K. The effect of democracy and press freedom on corruption: an empirical test. Economics letters, v. 85, n. 1, p. 93-101, 2004.

COLE, Daniel H; GROSSMAN, Peter Z. When is command-and-control efficient? Institutions, technology, and the comparative efficiency of alternative regulatory regimes for environmental protection. In: THE THEORY and Practice of Command and Control in Environmental Policy. London: Routledge, 2018. p. 115-166.

CORRUPÇÃO desvia R \$ 200 bi, por ano, no Brasil, diz coordenador da Lava Jato. Disponível em: < https://politica.estadao.com.br/blogs/fausto-macedo/corrupcao-desvia-r-200-bi-por-ano-no-brasil-diz-coordenador-da-lava-jato/>. Acesso em: 21 jun. 2019.

COSTA, Samia. Do freedom of information laws decrease corruption? The Journal of Law, Economics, \& Organization, v. 29, n. 6, p. 1317-1343, 2012.

FIGUEIREDO, Miguel FP de; HIDALGO, F Daniel; KASAHARA, Yuri. When do voters punish corrupt politicians? Experimental evidence from Brazil. Unpublished manuscript, UC Berkeley, 2011.

DI TELLA, Rafael; SCHARGRODSKY, Ernesto. The role of wages and auditing during a crackdown on corruption in the city of Buenos Aires. The Journal of Law and Economics, v. 46, n. 1, p. 269-292, 2003.

DJANKOV, Simeon et al. Disclosure by politicians. American Economic Journal: Applied Economics, v. 2, n. 2, p. 179-209, 2010.

DOIG, Alan; RILEY, Stephen. Corruption and anti-corruption strategies: Issues and case studies from developing countries. Corruption and integrity improvement initiatives in developing countries, v. 45, p. 62, 1998.

DOIG, Alan; WATT, David; WILLIAMS, Robert. Why do developing country anti-corruption commissions fail to deal with corruption? Understanding the three dilemmas of organisational development, performance expectation, and donor and government cycles. Public Administration and Development, v. 27, n. 3 , p. 251-259, 2007.

FERRAZ, Claudio; FINAN, Frederico. Electoral accountability and corruption: Evidence from the audits of local governments. The American Economic Review, v. 101, n. 4, p. 1274-1311, 2011.

FERRAZ, Claudio; FINAN, Frederico. Exposing corrupt politicians: the effects of Brazil's publicly released audits on electoral outcomes. The Quarterly Journal of Economics, v. 123, n. 2, p. 703-745, 2008.

FRIDOLFSSON, Sven-Olof et al. Fines, Leniency and Rewards in Antitrust. An Experiment. 2009.

GENTZKOW, Matthew; GLAESER, Edward L; GOLDIN, Claudia. The rise of the fourth estate. How newspapers became informative and why it mattered. In: GLAESER, Edward L; GOLDIN, Claudia (org.). Corruption and Reform: Lessons from America's Economic History. Chicago: University of Chicago Press, 2006. p. 187-230.

GOKCEKUS, Omer; MUKHERJEE, Ranjana. Officials' Asset Declaration Laws: Do They Prevent Corruption? Global Corruption Report, 2006.

GOMES, Reginaldo Gonçalves. Responsabilidade Administrativa do Servidor Público na Administração Pública Federal. Prisma Jurídico, v. 13, n. 1, p. 193-212, 2014.

HAMAGUCHI, Yasuyo; KAWAGOE, Toshiji; SHIBATA, Aiko. Group size effects on cartel formation and the enforcement power of leniency programs. International Journal of Industrial Organization, v. 27, n. 2, p. 145-165, 2009. 
HAQUE, Nadeem U1; SAHAY, Ratna. Do government wage cuts close budget deficits? Costs of corruption. Staff Papers, v. 43, n. 4, p. 754-778, 1996.

HOUGH, Dan. Corruption, anti-corruption and governance. UK: Palgrave Macmillan, 2013.

HUI, Wingchi. Combating Corruption: The Hong Kong Experience. Tsinghua China Law Review, v. 6, 2013.

HUSSMANN, Karen; HECHLER, Hannes; PEÑAILILLO, Miguel. Institutional arrangements for corruption prevention: Considerations for the implementation of the United Nations Convention against Corruption Article 6. U4 Issue, v. 2009, n. 4, 2009.

JOHNSØN, Jesper; TAXELL, Nils; ZAUM, Dominik. Mapping evidence gaps in anti-corruption: Assessing the state of the operationally relevant evidence on donors' actions and approaches to reducing corruption. U4 Issue, v. 2012, n. 7, 2012.

KAHNEMAN, Daniel. Thinking, fast and slow. New York: Macmillan, 2011.

KAUFMANN, Daniel. Corruption: the facts. Foreign policy, p. 114-131, 1997.

KLITGAARD, Robert. Incentive myopia. World Development, v. 17, n. 4, p. 447-459, 1989.

KOLSTAD, Ivar; WIIG, Arne. Is transparency the key to reducing corruption in resource-rich countries? World development, v. 37, n. 3, p. 521-532, 2009.

LAMBSDORFF, Johann. The Organization of Anticorruption: Getting Incentives Right. In: CORRUPTION, global security, and world order. Baltimore: Brookings Institution Press, 2009. p. 389-415.

LAMBSDORFF, Johann; NELL, Mathias. Fighting corruption with asymmetric penalties and leniency. CEGE Discussion Papers, 2007.

LESSIG, Lawrence. Republic, lost: how money corrupts congress--and a plan to stop it. New York: Hachette UK, 2011.

LINDSTEDT, Catharina; NAURIN, Daniel. Transparency is not Enough: Making Transparency Effective in Reducing Corruption. International Political Science Review, v. 31, n. 3, p. 301-322, 2010.

MELO, Marcus André. Brazil: democracy and corruption. Rio de Janeiro: Casa das Garças, 2014.

MORGAN, Bronwen; YEUNG, Karen. Regulatory instruments and techniques. In: AN INTRODUCTION to Law and Regulation: Text and Materials. Cambridge: Cambridge University Press, 2007. p. 79-150. (Law in Context). Disponível em: https:/ /www.cambridge.org/core/books/an-introduction-to-law-and-regulation/regulatory-instruments-and-techniques/AB3E72F0913ED482DC2F9229E74E1C03.

MOTTA, Massimo; POLO, Michele. Leniency programs and cartel prosecution. International journal of industrial organization, v. 21, n. 3, p. 347-379, 2003.

OGUS, Anthony. Corruption and regulatory structures. Law \& Policy, v. 26, n. 3-4, p. 329-346, 2004.

OLIVEIRA, Marina Gandra Camargo de Barros; RODRIGUES, Karina Furtado. Transparência em contas públicas no âmbito local no Brasil. In: MOHALLEM, Michael Freitas; RAGAZZO, Carlos Emmanuel Joppert (org.). Diagnóstico institucional: primeiros passos para um plano nacional anticorrupção. Rio de Janeiro: Escola de Direito do Rio de Janeiro da Fundação Getulio Vargas, 2017.

OLKEN, Benjamin A. Monitoring corruption: evidence from a field experiment in Indonesia. Journal of political Economy, v. 115, n. 2, p. 200-249, 2007.

PAES, Eneida Bastos. A construção da Lei de Acesso à Informação Pública no Brasil: desafios na implementação de seus princípios. Revista do Serviço Público, v. 62, n. 4, p. 407-423, 2014.

PEISAKHIN, Leonid; PINTO, Paul. Is transparency an effective anti-corruption strategy? Evidence from 
a field experiment in India. Regulation \& Governance, v. 4, n. 3, p. 261-280, 2010.

PEREIRA, Carlos; MELO, Marcus André. Reelecting corrupt incumbents in exchange for public goods: Rouba mas faz in Brazil. Latin American Research Review, p. 88-115, 2015.

POWER, Timothy Joseph; TAYLOR, Matthew MacLeod. Corruption and democracy in Brazil: the struggle for accountability. Notre Dame: University of Notre Dame Press, 2011.

PRADO, Mariana Mota; CARSON, Lindsey. Brazilian anti-corruption legislation and its enforcement: potential lessons for institutional design. RIBA Working Paper n. 09, 2014.

PRAT, Andrea. The wrong kind of transparency. 2003.

PUNIÇÃO a corruptos tem apenas valor simbólico, diz pesquisadora. 16/12/2013 - Poder. Folha de S.Paulo. Disponível em: <http://www1.folha.uol.com.br/poder/2013/12/1386052-punicao-a-corruptos-tem-apenas-valor-simbolico-diz-pesquisadora.shtml>. Acesso em: 1 set. 2017.

RAUCH, James E; EVANS, Peter B. Bureaucratic structure and bureaucratic performance in less developed countries. Journal of public economics, v. 75, n. 1, p. 49-71, 2000.

REINIKKA, Ritva; SVENSSON, Jakob. The power of information: Evidence from a newspaper campaign to reduce capture. US: World Bank Publications, 2004.

RIOS-FÍGUEROA, Julio. Justice system institutions and corruption control: evidence from Latin America. Justice System Journal, v. 33, n. 2, p. 195-214, 2012.

ROSE-ACKERMAN, Susan. The economics of corruption. Journal of public economics, v. 4, n. 2, p. 187-203, 1975.

ROSE-ACKERMAN, Susan. The law and economics of bribery and extortion. Annual Review of Law and Social Science, v. 6, p. 217-238, 2010.

ROSE-ACKERMAN, Susan; PALIFKA, Bonnie J. Corruption and government: Causes, consequences, and reform. New York: Cambridge University Press, 2016.

ROSE-ACKERMAN, Susan; TRUEX, Rory. Corruption and policy reform. 2012.

RYVKIN, Dmitry; SERRA, Danila. How corruptible are you? Bribery under uncertainty. Journal of Economic Behavior \& Organization, v. 81, n. 2, p. 466-477, 2012.

SCHIKORA, Jan Theodor. Bringing good and bad whistle-blowers to the lab. University of Munich: Munich discussion paper, 2011.

SEQUEIRA, Sandra; DJANKOV, Simeon. An empirical study of corruption in ports. 2010.

SHLEIFER, Andrei; VISHNY, Robert W. Corruption. The quarterly journal of economics, v. 108, n. 3, p. 599617, 1993.

SIRICO JR, Louis J. Agencies in Conflict: Overlapping Agencies and the Legitimacy of the Administrative Process. Vand. L. Rev., v. 33, p. 101, 1980.

SPAGNOLO, Giancarlo. Divide et impera: Optimal leniency programs CEPR Discussion Papern. 4840, 2004.

SPAGNOLO, Giancarlo. Leniency and whistleblowers in antitrust. In: BUCCIROSSI, Paolo (org.). Handbook of Antitrust Economics. Cambridge: MIT Press, 2006.

SPAGNOLO, Giancarlo. Optimal leniency programs. FEEM Working Paper n. 42, 2000.

SUNSTEIN, Cass R; ULLMANN-MARGALIT, Edna. Second-order decisions. Ethics, v. 110, n. 1, p. 5-31, 1999.

SUTTER, Daniel. Media scrutiny and the quality of public officials. Public Choice, v. 129, n. 1-2, p. 25-40, 
2006.

SVENSSON, Jakob. Eight questions about corruption. The Journal of Economic Perspectives, v. 19, n. 3, p. 1942, 2005.

TANGRI, Roger; MWENDA, Andrew M. Politics, donors and the ineffectiveness of anti-corruption institutions in Uganda. The Journal of Modern African Studies, v. 44, n. 1, p. 101-124, 2006.

TANZI, Vito; SHOME, Parthasarathi. A primer on tax evasion. Staff Papers-International Monetary Fund, p. 807-828, 1993.

TAYLOR, Matthew M. Veto and voice in the courts: policy implications of institutional design in the Brazilian judiciary. Comparative Politics, p. 337-355, 2006.

TEACHOUT, Zephyr. Corruption in America. Cambridge: Harvard University Press, 2014.

TREISMAN, Daniel. The causes of corruption: a cross-national study. Journal of public economics, v. 76, n. 3 , p. 399-457, 2000.

TVERSKY, Amos; KAHNEMAN, Daniel. Advances in prospect theory: Cumulative representation of uncertainty. Journal of Risk and uncertainty, v. 5, n. 4, p. 297-323, 1992.

VAN RIJCKEGHEM, Caroline; WEDER, Beatrice. Bureaucratic corruption and the rate of temptation: do wages in the civil service affect corruption, and by how much? Journal of development economics, v. 65 , n. 2 , p. 307-331, 2001.

WINTERS, Matthew S; TESTA, Paul; FREDRICKSON, Mark M. Chapter 8 Using Field Experiments to Understand Information as an Antidote to Corruption. In: SERRA, Danila; WANTCHEKON, Leonard (org.). New Advances in Experimental Research on Corruption. Bingley: Emerald Group Publishing Limited, 2012. v. 15. p. 213-246. (Research in Experimental Economics).

WINTERS, Matthew S; WEITZ-SHAPIRO, Rebecca. Lacking information or condoning corruption: When do voters support corrupt politicians? Comparative Politics, v. 45, n. 4, p. 418-436, 2013.

YEUNG, Karen. Government by publicity management: Sunlight or spin. Public Law, v. 2, p. 360-383, 2005.

ZAMBONI, Yves; LITSCHIG, Stephan. Audit risk and rent extraction: Evidence from a randomized evaluation in Brazil. Universitat Pompeu Fabra, 2013. 
Para publicar na revista Brasileira de Políticas Públicas, acesse o endereço eletrônico www.rbpp.uniceub.br

Observe as normas de publicação, para facilitar e agilizar o trabalho de edição. 